\title{
Modeling Nucleation and Growth of Zinc Oxide During Discharge of Primary Zinc-Air Batteries
}

\author{
Johannes Stamm ${ }^{\mathrm{a}, \mathrm{b}, \mathrm{c}}$, Alberto Varzi ${ }^{\mathrm{a}, \mathrm{d}}$, Arnulf Latz ${ }^{\mathrm{a}, \mathrm{b}, \mathrm{e}}$, Birger Horstmann ${ }^{\mathrm{a}, \mathrm{b}, *}$ \\ ${ }^{a}$ Helmholtz Institute Ulm (HIU), Helmholtzstraße 11, 89081 Ulm, Germany \\ ${ }^{b}$ German Aerospace Center (DLR), Institute of Engineering Thermodynamics, Pfaffenwaldring 38-40, 70569 Stuttgart, Germany \\ ${ }^{c}$ Institute for Computational and Applied Mathematics, Universität Münster, Einsteinstraße 62, 48149 Münster, Germany \\ ${ }^{d}$ Karlsruhe Institute of Technology (KIT), PO Box 3640, 76021 Karlsruhe, Germany \\ ${ }^{e}$ Ulm University, Institute of Electrochemistry, Albert-Einstein-Allee 47, 89069 Ulm, Germany
}

\begin{abstract}
Metal-air batteries are among the most promising next-generation energy storage devices. Relying on abundant materials and offering high energy densities, potential applications lie in the fields of electro-mobility, portable electronics, and stationary grid applications. Now, research on secondary zinc-air batteries is revived, which are commercialized as primary hearing aid batteries. One of the main obstacles for making zinc-air batteries rechargeable is their poor lifetime due to the degradation of alkaline electrolyte in contact with atmospheric carbon dioxide. In this article, we present a continuum theory of a commercial Varta PowerOne button cell. Our model contains dissolution of zinc and nucleation and growth of zinc oxide in the anode, thermodynamically consistent electrolyte transport in porous media, and multi-phase coexistance in the gas diffusion electrode. We perform electrochemical measurements and validate our model. Excellent agreement between theory and experiment is found and novel insights into the role of zinc oxide nucleation and growth and carbon dioxide dissolution for discharge and lifetime is presented. We demonstrate the implications of our work for the development of rechargeable zinc-air batteries.
\end{abstract}

Highlights

- Modeling and simulating of VARTA button cell

- Validation of galvanostatic discharge and lifetime analysis

- Nucleation and growth of $\mathrm{ZnO}$ and its impact on discharge curve

- Degradation due to carbonation of alkaline electrolyte

Keywords: zinc-air battery, primary button cell, aqueous alkaline electrolyte, model and validation, carbon dioxide absorption, nucleation and growth

\section{Introduction}

Energy production by renewable energies, i.e., wind or solar power, is fluctuating. Therefore, special efforts are required to match energy production and consumption. Traditional power plants are not ideal to compensate for energy fluctuations, especially because renewable energies are strongly decentralized. Furthermore, portable electronic devices and electro-mobility rely on compact energy storage devices. Metal-air batteries are

\footnotetext{
${ }^{*}$ Corresponding author

Email address: birger.horstmann@dlr.de (Birger Horstmann)
}

promising candidates to fulfill this demand, because of their high specific energy density and the use of cheap and abundant materials. These batteries are open at the cathode and use atmospheric oxygen.

Several metals, e.g., lithium, sodium, and zinc, are potential active anode materials in metal-air cells [1]. The high theoretical energy density of lithium-air batteries has stimulated a lot of research [2]. For aprotic electrolytes, the challenge is to influence growth mechanisms in order to maximize capacity, while maintaining sufficient reversibility [3, 4, 5, 6, 7, 8, 9]. Aqueous lithium-air batteries require a stable lithium conducting anode protection [10, 11, 12, 13]. Non-aqueous sodium-air cells rely 
on cheap materials having similar challenges as lithium-air batteries $[14,15,16]$.

Zinc-air batteries stand out as the single commercialized metal-air battery. Primary zinc-air button-cells have a long history in hearing aids. Therefore, also rechargeable zinc-air batteries are in a very mature state $[1,17,18,19,20,21]$. The discharge product is not passivating and crystallization is reversible. Metallic zinc ( $\mathrm{Zn}$ ) anodes are stable in aqueous electrolytes and can withstand a few hundred cycles. The cells can work with ambient air for a few months. The theoretical specific energy density of zinc-air batteries reaches $1100 \mathrm{Wh} \mathrm{kg}^{-1}$ with respect to the mass of $\mathrm{Zn}$ [1]. The button cell studied in this work delivers the practical energy density $300 \mathrm{Wh} \mathrm{kg}^{-1}$ at $100 \mathrm{Am}^{-2}$, which is still about three times as high as batteries in modern electric vehicles [22].

Besides its energy density, zinc-air cells offer a couple of additional advantages, e.g., comparatively constant discharge voltage, long storage life, no reaction with water, large abundance of $\mathrm{Zn}$, low costs, and high environmental safety [23]. However, unsolved issues for secondary zinc-air cells remain, particularly with respect to cycle life and lifetime. Major challenges are passivation due to zinc oxide $(\mathrm{ZnO})$ precipitation, shape changes of metallic $\mathrm{Zn}$ during cycling, and sluggish kinetics of oxygen reduction [1].

Furthermore, atmospheric carbon dioxide enters the cell and reacts to carbonate in the electrolyte [24, 25]. This process entails an irreversible reduction of hydroxide concentration, zincate solubility, and electrolyte conductivity. Therefore, without special precautions, the lifetime of alkaline zinc-air batteries is limited to a few months, which is especially troublesome for secondary cells.

Most research on zinc-air batteries is devoted to improving the alkaline system [17], based on modeling [26], in-situ $\mathrm{x}$-ray measurements [27], and designing nano-materials [19]. Novel research makes use of alternative electrolytes, i.e., aqueous neutral electrolytes [28] to mitigate carbonate formation or ionic liquids [29] to enable reversible $\mathrm{Zn}$ deposition.

In order to improve the cycle life of zinc-air batteries, a better understanding of its elementary processes seems necessary. To address this issue, several models on zinc-air cells are discussed in the literature [30, 31, 32, 25], based on the general, macroscopic, and one-dimensional model for porous electrodes proposed by Newman et al. [33, 34].

Sunu and Bennion [30] develop a one dimensional, time dependent model of the $\mathrm{Zn}$ anode of zinc-air batteries, based on concentrated ternary electrolyte theory [34]. It is found that electrolyte convection in $\mathrm{Zn}$ anodes can lead to a redistribution of $\mathrm{Zn}$ inside the anode and into the cathode upon cycling. The redistributed $\mathrm{Zn}$ blocks electrolyte pores or electrically shortens the cell. Isaacson et al. [35] discuss a similar, but two dimensional model for $\mathrm{Zn}$ electrodes.

Mao and White [31] extend Sunu's model resolving the separator region. It is found that potassium zincate does not precipitate under realistic conditions [36]. Deiss et al. [32] describe a similar model for secondary zinc-air cells based on dilute solution theory, which reaches a fairly good agreement with experimental discharge curves.

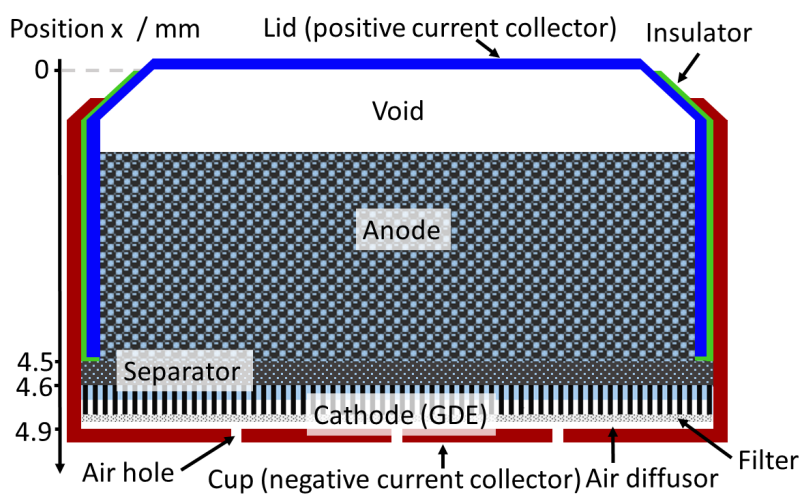

Figure 1. Components and structure of a zinc-air button cell.

Schröder and Krewer [25] develop a model of secondary cells, including a gas diffusion electrode and the effect of atmospheric carbon dioxide. As this model is zero-dimensional, it cannot resolve the nonuniform reaction distribution in the $\mathrm{Zn}$ anode [27]. The model demonstrates the reduction in lifetime due to carbonization of the alkaline electrolyte.

In this paper, we develop a one dimensional model for both porous electrodes. Three-phase-coexistence in the gas diffusion electrode $[12,13]$ and inhomogeneous reaction distributions in the $\mathrm{Zn}$ anode are modeled at the same time. The electrolyte transport model is based on rational thermodynamics taking into account diffusion, migration, and convection [37, 38]. For the first time in zinc-air batteries, we model the nucleation and growth of $\mathrm{ZnO}$ and its impact on $\mathrm{Zn}$ dissolution. The kinetics of carbon dioxide absorption is described as first order reaction based on a microscopic model [39]. Our model is parametrized and validated with the commercial zinc-air coin cell Varta PowerOne PR44 Type p675 used for hearing aids. We can correlate characteristic features in the discharge curves with specific processes inside the battery, e.g., nucleation of $\mathrm{ZnO}$ and diffusion of reactants through $\mathrm{ZnO}$. The limited battery lifetime is explained with carbonation of the electrolyte.

Our paper is structured as follows: First, we give a brief overview of cell design, composition, and the chemical reactions during the discharge process (see Sec. 2). Next, we describe our homogeneous, one-dimensional, continuum cell model (see Sec. 3) and its parameterization (see Sec. 4). Then, we discuss galvanostatic discharge (see Sec. 6) and lifetime (see Sec. 7). In each of these two sections, we compare experiments and simulations. The excellent agreement between theory and experiment allows the discussion of internal battery processes based on simulations. Finally, we summarize our findings in Sec. 8.

\section{Zinc-Air Button Cell}

In this section, we describe the structure and components of the Varta PowerOne hearing aid battery PR44 Type p675 (see Fig. 1). Anode, separator, cathode, and electrolyte are important for cell performance and described in the subsequent sections. 


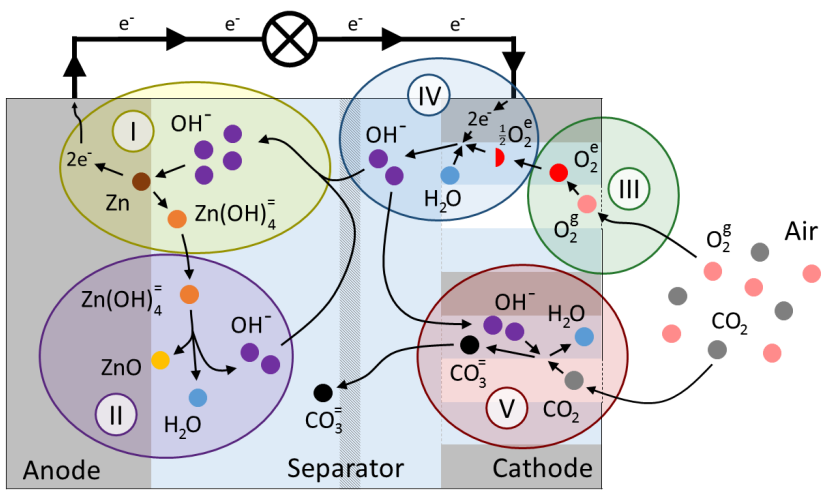

Figure 2. Reactions in the primary zinc-air cell: I) $\mathrm{Zn}$ dissolution, II) $\mathrm{ZnO}$ precipitation, III) Oxygen absorption into the electrolyte, IV) Oxygen reduction, V) Dissolution of atmospheric carbon dioxide and carbonate formation.

\subsection{Composition and Design of Zinc-Air Button Cells}

The porous anode consists of metallic $\mathrm{Zn}$ powder connected to the current collector. The pores are flooded with electrolyte. $\mathrm{Zn}$ as active material dissolves during discharge at the solidliquid phase boundary. The fine powder with its large surface area provides a fast and homogeneous $\mathrm{Zn}$ dissolution. A void space beneath the cover of the anode accommodates the volume change due to the conversion of active material in the anode. We assume that this void space is filled with gas at standard pressure which does not interact with the cell, but can leave it through the gas diffusion electrode (GDE).

The electrolyte in the VARTA cell is an aqueous potassium hydroxide solution at 32 weight $\%$. This electrolyte is optimized for conductivity realizing the best combination of ionic strength and viscosity. Additionally, this potassium hydroxide solution offers fast oxygen reduction kinetics.

The separator is made of a microporous filtering paper. It prevents electric contact between the two electrodes, but allows the electrolyte to pass through.

As cathode, metal-air batteries employ a gas diffusion electrode (GDE) which fulfills two functions. On the one hand, it supplies the cell with atmospheric oxygen, but keeps the electrolyte inside the cell. To this aim, the GDE contains a hydrophobic binder, repelling the aqueous electrolyte and enabling the coexistence of gas and liquid phases. On the other hand, the GDE reduces dissolved oxygen, providing hydroxide to the electrolyte. The cathode is filled with a non-noble catalyst, i.e., manganese oxide, to improve reaction kinetics at low costs. The specific surface area for oxygen reaction is enlarged by using a highly porous structure [20].

\subsection{Reactions}

The main reactions in a zinc-air battery are shown in Fig. 2. During discharge the anodic $\mathrm{Zn}$ is oxidized. However, $\mathrm{Zn}$ does not directly transform into $\mathrm{ZnO}$, but dissolves as zincate $\mathrm{Zn}(\mathrm{OH})_{x}^{y-}$ into the electrolyte. The dominant type in the strongly alkaline electrolyte is $\mathrm{Zn}(\mathrm{OH})_{4}^{=}$[40], and we assume this is the only $\mathrm{Zn}$ species in the electrolyte. The chemical equation for the oxidation is

$$
\mathrm{Zn}+4 \mathrm{OH}^{-} \rightleftharpoons \mathrm{Zn}(\mathrm{OH})_{4}^{=}+2 \mathrm{e}^{-} .
$$

The overall reaction can be divided into elementary first order reactions. Several reaction mechanisms are suggested with three $[41,42]$ or four elementary reactions $[43,30]$

$$
\begin{aligned}
\mathrm{Zn}+\mathrm{OH}^{-} & \rightleftharpoons \mathrm{Zn}(\mathrm{OH})+\mathrm{e}^{-} \\
\mathrm{ZnOH}+\mathrm{OH}^{-} & \rightleftharpoons \mathrm{Zn}(\mathrm{OH})_{2}^{-} \\
\mathrm{Zn}(\mathrm{OH})_{2}^{-}+\mathrm{OH}^{-} & \rightleftharpoons \mathrm{Zn}(\mathrm{OH})_{3}^{-}+\mathrm{e}^{-} \\
\mathrm{Zn}(\mathrm{OH})_{3}^{-}+\mathrm{OH}^{-} & \rightleftharpoons \mathrm{Zn}(\mathrm{OH})_{4}^{=} .
\end{aligned}
$$

In both cases oxidation of $\mathrm{Zn}(\mathrm{OH})_{2}^{-}$is found to be rate limiting.

If the zincate concentration raises above its solubility limit, precipitation of $\mathrm{ZnO}$ becomes possible thermodynamically

$$
\mathrm{Zn}(\mathrm{OH})_{4}^{=} \rightleftharpoons \mathrm{ZnO}+\mathrm{H}_{2} \mathrm{O}+2 \mathrm{OH}^{-} .
$$

The reaction takes place on the $\mathrm{Zn}$ surface and forms a porous $\mathrm{ZnO}$ layer, which retards the hydroxide supply of the anode. Thereby, it reduces the cell voltage and passivates the electrode once the layer is getting to thick [44, 30]. If the overvoltage at the $\mathrm{Zn}$ surface becomes too large, $\mathrm{ZnO}$ type II forms as a compact $\mathrm{ZnO}$ layer and completely passivates the $\mathrm{Zn}$. We omit $\mathrm{ZnO}$ type II in our model, since the cell voltage in our experiments does not allow its formation in the typical working domain $U>1.1 \mathrm{~V}$ [42].

In the GDE at the gas-liquid phase boundary, atmospheric oxygen is dissolved [45] in the electrolyte

$$
\mathrm{O}_{2}^{\mathrm{g}} \rightleftharpoons \mathrm{O}_{2}^{\mathrm{e}} \text {. }
$$

Subsequently, dissolved oxygen is reduced to hydroxide at the active cathode surfaces

$$
0.5 \mathrm{O}_{2}^{\mathrm{e}}+\mathrm{H}_{2} \mathrm{O}+2 \mathrm{e}^{-} \rightleftharpoons 2 \mathrm{OH}^{-} .
$$

The kinetics of oxygen reduction can be understood based on its elementary reaction steps $[46,47]$ and depends on the employed catalyst [48].

The carbonate reaction is the major degradation process [24]. Atmospheric carbon dioxide dissolves and reacts to carbonate [36]

$$
\mathrm{CO}_{2}+2 \mathrm{OH}^{-} \rightleftharpoons \mathrm{CO}_{3}^{=}+\mathrm{H}_{2} \mathrm{O} \text {. }
$$

In an alkaline medium the rate limiting reaction step is [49]

$$
\mathrm{CO}_{2}+\mathrm{OH}^{-} \stackrel{k_{\mathrm{OH}^{-}}}{\longrightarrow} \mathrm{HCO}_{3}^{-}
$$

immediately followed by the reaction

$$
\mathrm{HCO}_{3}^{-}+\mathrm{OH}^{-} \longrightarrow \mathrm{CO}_{3}^{=}+\mathrm{H}_{2} \mathrm{O} \text {. }
$$

The carbonate has various negative effects on the cell performance. The concentration of hydroxide, the main charge carrier, decreases. This leads to a loss of conductivity and enhances the passivation of the anode. Furthermore, carbonate inhibits both of the electrochemical reactions, because the decrease in hydroxide concentration reduces the solubilities of zincate and oxygen. 


\section{Physical and Mathematical Model}

In this section, we introduce a thermodynamically consistent model for zinc-air cells. Our continuum model represents effects on a single dimension connecting anode, separator, and cathode. We start with a simple diffusion-migration model and successively add convection and reactions to it. First, we state a few central assumptions which keep our model simple:

- We model an isothermal system since temperature variations are negligible in small zinc-air button cells.

- The electrolyte is locally charge neutral because we are not interested in capacitive effects.

- The electrolyte is strictly incompressible, i.e., its volume does not respond to pressure.

- The partial pressures in the gas phase are constant because it is connected to the atmosphere and transport of gases is significantly faster than transport in the electrolyte.

- No electrolyte is leaking out off the battery. Consequently, all electrolyte fluxes equal zero on the simulation domain boundaries.

In the following, we denote the solvent $\mathrm{H}_{2} \mathrm{O}$, the three kinds of anions $\mathrm{OH}^{-}, \mathrm{Zn}(\mathrm{OH})_{4}^{=}, \mathrm{CO}_{3}^{=}$, and the cation $\mathrm{K}^{+}$with the indices $0,1,2,3$, and + , respectively.

\subsection{Electrolyte Diffusion and Migration}

We model diffusion and migration based on Latz et al. [37, 38]. In this subsection, we discuss transport neglecting volume changes, chemical reactions, and convection. The latter means that we describe transport relative to the center of mass motion of the electrolyte. In the following subsections, we will step by step develop a realistic model with volume changes and chemical reactions, as well as convection. In the first part of this section, we present our model for pure electrolytes.

Dissolved oxygen can diffuse in the electrolyte

$$
\partial_{t} c_{\mathrm{O}^{2}}=\vec{\nabla} \cdot\left(D_{\mathrm{O}^{2}} \vec{\nabla} c_{\mathrm{O}^{2}}\right) .
$$

For the sake of clarity, we omit the dissolved oxygen below, knowing that it appears only in small amounts and does not influence the transport of the dominant species. According to Latz et al. [38], the entropy production rate in polarizable systems in an external electromagnetic field in the isothermal case is

$$
\mathcal{R}=-\vec{j} \cdot \vec{\nabla} \Phi-\sum_{i=1}^{3} \vec{N}_{i} \cdot \vec{\nabla} \mu_{i}
$$

Here $\vec{N}_{i}$ denotes the particle flux density of species $i, \vec{j}$ the current density, $\mu_{i}:=-\tilde{\mu}_{0}\left(M_{i}+z_{i} M_{+}\right) M_{0}^{-1}+\tilde{\mu}_{i}+z_{i} \tilde{\mu}_{+}$the effective chemical potential and $\Phi$ the electrical potential, which holds $\vec{E}=-\vec{\nabla} \Phi$. The effective chemical potentials $\mu_{i}$ for the anions are valid in the center-of-mass frame assuming local charge neutrality.
The thermodynamical fluxes $\vec{j}$ and $\vec{N}_{i}$ fulfill the Onsager reciprocal relations, which we write compactly as

$$
\left(-\vec{N}_{1},-\vec{N}_{2},-\vec{N}_{3},-\vec{\iota}\right)^{T}=\mathcal{M} \cdot\left(\vec{\nabla} \mu_{1}, \vec{\nabla} \mu_{2}, \vec{\nabla} \mu_{3}, \vec{\nabla} \phi\right)^{T},
$$

with the scaling $\vec{\imath}:=\vec{j} F^{-1}$ and $\phi:=\Phi F$. In this scaling, the Onsager matrix $\mathcal{M}$ is defined as

$$
\mathcal{M}:=\mathcal{D}+\tilde{\kappa} \vec{\tau} \otimes \vec{\tau}
$$

with $\tilde{\kappa} \quad:=\quad \kappa F^{-2}, \quad \mathcal{D}:=\operatorname{diag}\left(\tilde{D}_{1}, \tilde{D}_{2}, \tilde{D}_{3}, 0\right)$, and $\vec{\tau}:=\left(-\tau_{1},-\tau_{2},-\tau_{3}, 1\right)^{T}$ with $\tau_{i}:=t_{i} z_{i}^{-1}$. Here $t_{i}, \kappa$ and $F$ denote the transference numbers, the electrolytic conductivity and the Faraday constant, respectively.

The Onsager matrix has to be positive-semidefinite, since the entropy production rate $\mathcal{R}$ is always non-negative in a physical system. This is obviously fulfilled, if $\tilde{D}_{i} \geq 0$ and $\tilde{\kappa} \geq 0$, due to the simple calculation

$$
\vec{x}^{T} \mathcal{M} \vec{x}=\sum_{i=1}^{n} \tilde{D}_{i} x_{i}^{2}+\tilde{\kappa}(\vec{x} \cdot \vec{\tau}) .
$$

The consequences of the reciprocal relations for the thermodynamical fluxes are more apparent in the standard notation. We express these equations in terms of concentrations, which is more convenient. Assuming that the chemical potential $\mu_{i} \equiv$ $\mu_{i}\left(c_{i}\right)$ of any species depends on the corresponding concentration only, we find

$$
\begin{aligned}
\vec{N}_{i} & =-D_{i} \vec{\nabla} c_{i}-\frac{t_{i}}{z_{i} F} \vec{j} \\
\vec{j} & =-\kappa \vec{\nabla} \Phi+\frac{\kappa}{F} \sum_{i=1}^{3} \frac{t_{i}}{z_{i}}\left(\frac{\partial \mu_{i}}{\partial c_{i}}\right) \vec{\nabla} c_{i} .
\end{aligned}
$$

with $D_{i}:=\tilde{D}_{i}\left(\frac{\partial \mu_{i}}{\partial c_{i}}\right)$ denoting the diffusion coefficients.

In the absence of reactions, concentration and charge density are conserved. Taking the local charge neutrality of the electrolyte into account, they satisfy the continuity equations

$$
\partial_{t} c_{i}=-\vec{\nabla} \cdot \vec{N}_{i} \quad \text { and } \quad 0=-\vec{\nabla} \cdot \vec{j} .
$$

Combining these relations with Eqs. 6 and 7, we finally find the transport equations

$$
\begin{aligned}
\partial_{t} c_{i} & =\vec{\nabla} \cdot\left(D_{i} \vec{\nabla} c_{i}\right)+\vec{\nabla} \cdot\left(\frac{t_{i}}{z_{i} F} \vec{j}\right) \\
0 & =\vec{\nabla} \cdot(\kappa \vec{\nabla} \Phi)-\vec{\nabla} \cdot\left(\frac{\kappa}{F} \sum_{i=1}^{3} \frac{t_{i}}{z_{i}}\left(\frac{\partial \mu_{i}}{\partial c_{i}}\right) \vec{\nabla} c_{i}\right) .
\end{aligned}
$$

In the second part of this section, we consider the electrodes. Therefore, we now allow three coexisting phases: gas, liquid, and solid.

Taking the porous electrode into account changes the model in two ways: fluxes in porous media differ from unhindered fluxes in pure liquids and the transport equations are only applied to the electrolyte volume. 
We define the volume fraction of each phase as $\epsilon_{i}:=\frac{V_{i}}{V_{\text {total }}}$. This definition obviously yields

$$
1=\epsilon_{\mathrm{s}}+\epsilon_{\mathrm{e}}+\epsilon_{\mathrm{g}},
$$

where the indices s, g, and e denote the solid phase, the gas phase, and the electrolyte, respectively. In agreement with Ref. [34], we model the effects of porosity and tortuosity on the fluxes via the factor $\epsilon_{\mathrm{e}}^{\beta}$, with the Bruggeman coefficient $\beta=1.5$.

The effective flux density equations are (see eq. 6,7 )

$$
\begin{aligned}
\vec{N}_{i}^{\mathrm{eff}} & =-\epsilon_{\mathrm{e}}^{\beta} D_{i} \vec{\nabla} c_{i}-\epsilon_{\mathrm{e}}^{\beta} \frac{t_{i}}{z_{i} F} \vec{j}, \\
\vec{j}^{\mathrm{eff}} & =-\epsilon_{\mathrm{e}}^{\beta} \kappa \vec{\nabla} \Phi+\frac{\epsilon_{\mathrm{e}}^{\beta} \kappa}{F} \sum_{i=1}^{3} \frac{t_{i}}{z_{i}}\left(\frac{\partial \mu_{i}}{\partial c_{i}}\right) \vec{\nabla} c_{i} .
\end{aligned}
$$

\subsection{Reactions in Porous Electrodes}

In this section, we incorporate the reactions described in Sec. 2.2 into our model. Then particle flux density and current density are not conserved quantities. In our macro-homogeneous approach, reactions appear as species-related source terms $S_{i}$ (see eq. 18) in the transport equations. Thus, the continuity Eqs. 8 become

$$
\begin{aligned}
\partial_{t}\left(\epsilon_{\mathrm{e}} c_{i}\right) & =-\vec{\nabla} \cdot \vec{N}_{i}^{\mathrm{eff}}+S_{i} \quad \text { and } \\
0 & =-\vec{\nabla} \cdot \vec{j}^{\mathrm{eff}}-\sum_{i=1}^{3} z_{i} F S_{i} .
\end{aligned}
$$

We find the macro-homogeneous transport equations with the definition of the effective fluxes 12 and 13

$$
\begin{array}{r}
\partial_{t}\left(\epsilon_{\mathrm{e}} c_{i}\right)=\vec{\nabla} \cdot\left(\epsilon_{\mathrm{e}}^{\beta} D_{i} \vec{\nabla} c_{i}\right)+\vec{\nabla} \cdot\left(\epsilon_{\mathrm{e}}^{\beta} \frac{t_{i}}{z_{i} F} \vec{j}\right)+S_{i} \\
0=-\sum_{i=1}^{3} z_{i} F S_{i}+\vec{\nabla} \cdot\left(\epsilon_{\mathrm{e}}^{\beta} \kappa \nabla \Phi\right) \\
-\vec{\nabla} \cdot\left(\frac{\epsilon_{\mathrm{e}}^{\beta} \kappa}{F} \sum_{i=1}^{3} \frac{t_{i}}{z_{i}}\left(\frac{\partial \mu_{i}}{\partial c_{i}}\right) \vec{\nabla} c_{i}\right) .
\end{array}
$$

The species-related source terms depend on the reaction-specific source terms $s_{j}$

$$
S_{i}=\sum_{j \in \mathcal{J}} s_{j} v_{i j},
$$

where $\mathcal{J}=\{\mathrm{I}, \ldots, \mathrm{V}\}$ denotes the set of all reaction indices and $v_{i j}$ the stoichiometric index of species $i$ in reaction $j$. The reaction-specific source terms $s_{j}$ are discussed in the following. Generally, the source terms $s_{i}=A_{i} \cdot j_{i}$ are the products of the surface-related reaction rates $j_{i}$ and the specific surface areas $A_{i}$

\subsubsection{Zn oxidation / dissolution}

To model the surface-related reaction rate of first order electrochemical reactions, a thermodynamically consistent ButlerVolmer approach is applied [50, 51].

$$
j=j_{0}\left[\exp \left(\alpha \frac{z F}{R T} \eta\right)-\exp \left(-(1-\alpha) \frac{z F}{R T} \eta\right)\right],
$$

with the exchange current density

$$
j_{0}:=k\left(\frac{c_{\mathrm{O}}}{c_{\mathrm{std}}}\right)^{(1-\alpha)}\left(\frac{c_{\mathrm{R}}}{c_{\mathrm{std}}}\right)^{\alpha}
$$

and the activation overpotential

$$
\eta=\eta^{0}+\frac{R T}{z F} \ln \left(\frac{c_{\mathrm{O}}}{c_{\mathrm{R}}}\right)
$$

Here $R, \alpha, z, c_{\mathrm{O}}$, and $c_{\mathrm{R}}$ denote the universal gas constant, the symmetry factor, the number of exchanged electrons, and the concentration of the oxidizing and the reducing agents, respectively. The second term on the right hand side takes the chemical potential differences into account, which are caused by the species concentrations in the electrolyte.

Even though the $\mathrm{Zn}$ oxidation is not an elementary oneelectron reaction (see Reaction I in Sec. 2.2), complex rate expressions based on the rate determining electron transfer exist $[30,43]$. As, however, diffusion through the $\mathrm{ZnO}$ layer is limiting $\mathrm{Zn}$ dissolution, we can employ the simpler consistent global rate expression $[32,25]$

$$
j_{\mathrm{I}}=2 k_{\mathrm{I}} \sqrt{\frac{c_{\mathrm{s}, \mathrm{OH}^{-}}^{4} c_{\mathrm{Zn}(\mathrm{OH})_{4}^{\bar{y}}}}{c_{\text {std }}^{5}}} \sinh \left(\frac{F}{R T} \eta_{\mathrm{a}}\right),
$$

where we choose the symmetry factor $\alpha=0.5$. Here $k_{\mathrm{I}}$ denotes the kinetic coefficient and $c_{\mathrm{s}, \mathrm{OH}^{-}}$the hydroxide concentration at the $\mathrm{Zn}$ surface, in contrast to the hydroxide bulk concentration $c_{\mathrm{OH}^{-}}=c_{\mathrm{b}, \mathrm{OH}^{-}}$. The overpotential yields

$$
\eta_{\mathrm{a}}=\Delta \phi_{\mathrm{a}}-\Delta \phi_{\mathrm{a}}^{0}+\frac{R T}{z F} \ln \left(\frac{c_{\mathrm{s}, \mathrm{OH}^{-}}^{4}}{c_{\mathrm{Zn}(\mathrm{OH})_{4}^{=}} c_{\mathrm{std}}^{3}}\right) .
$$

Thereby, $\Delta \phi_{\mathrm{a}}:=\phi_{\mathrm{a}}-\phi_{\mathrm{e}}$ is the potential difference between anode and electrolyte and $\Delta \phi_{\mathrm{a}}^{0}$ is the open circuit half-cell potential at standard concentrations.

For determining the specific surface area $A_{\mathrm{I}}$ of the anode, we assume that the $\mathrm{Zn}$ electrode consists of spherical particles with radius $r_{\mathrm{Zn}}$. Thus, the constant density of spherical $\mathrm{Zn}$ particles

$$
N_{\mathrm{Zn}}=\frac{3 \epsilon_{\mathrm{Zn}}^{0}}{4 \pi}\left(r_{\mathrm{Zn}}^{0}\right)^{-3}
$$

depends on initial volume fraction $\epsilon_{Z n}^{0}$ and radius $r_{Z n}^{0}$. At each time step and position, we calculate $\mathrm{Zn}$ radius and specific surface area according to

$$
r_{\mathrm{Zn}}=\left(\frac{3 \epsilon_{\mathrm{Zn}}}{4 \pi N_{\mathrm{Zn}}}\right)^{\frac{1}{3}}, \quad A_{\mathrm{I}}=4 \pi N_{\mathrm{Zn}} r_{\mathrm{Zn}}^{2} .
$$

The $\mathrm{ZnO}$ layer formed around dissolved $\mathrm{Zn}$ particles was imaged by Shao-Horn [52, 53]. First, $\mathrm{ZnO}$ type I forms a porous shell filled with electrolyte and the remaining $\mathrm{Zn}$ particle. We assume that the $\mathrm{ZnO}$ film forms uniformly with a constant porosity $\epsilon_{\mathrm{f}}$ on each of the $\mathrm{Zn}$ particles in a certain control volume. 
The film thickness is $\delta_{\mathrm{Zn}}:=r_{\mathrm{ZnO}}-r_{\mathrm{Zn}}^{0}$ with the constant inner radius $r_{\mathrm{Zn}}^{0}$ and the growing outer radius

$$
r_{\mathrm{ZnO}}=r_{\mathrm{Zn}}^{0}\left(1+\frac{1}{1-\epsilon_{\mathrm{f}}} \frac{\epsilon_{\mathrm{ZnO}}}{\epsilon_{\mathrm{Zn}}^{0}}\right)^{\frac{1}{3}} .
$$

The hydroxide concentration $c_{\mathrm{s}, \mathrm{OH}^{-}}$at the $\mathrm{Zn}$ surface is limited by diffusion through the porous film and by hydroxide consumption due to $\mathrm{Zn}$ oxidation $s_{\mathrm{I}}$ at the surface $[43,44]$. Hydroxide transport is described by spherical diffusion

$$
\frac{4 s_{\mathrm{I}}}{A_{\mathrm{I}}^{0}}=\epsilon_{\mathrm{f}}^{3.5} D_{\mathrm{OH}^{-}} \frac{c_{\mathrm{b}, \mathrm{OH}^{-}}-c_{\mathrm{s}, \mathrm{OH}^{-}}}{\delta_{\mathrm{Zn}}} \frac{r_{\mathrm{ZnO}}}{r_{\mathrm{Zn}}^{0}} .
$$

driven by the concentration gradient between the bulk $c_{\mathrm{b}, \mathrm{OH}^{-}}$ and surface $c_{\mathrm{s}, \mathrm{OH}^{-}}$concentration. We increase the Bruggemann coefficient to 3.5 here, in order to simulate the diffusion limitation proven experimentally. This value is realistic for compact materials $[54,55]$.

\subsubsection{Oxygen reduction}

We model the rate of oxygen reduction (see Reaction IV) via the symmetric Butler-Volmer approach [56]

$$
j_{\mathrm{IV}}=-2 k_{\mathrm{IV}} \frac{c_{\mathrm{OH}^{-}}}{c_{\mathrm{std}}} \sqrt[4]{\frac{c_{\mathrm{O}_{2}}}{c_{\mathrm{std}}}} \sinh \left(\frac{F}{R T} \eta_{\mathrm{c}}\right),
$$

with the activation overpotential

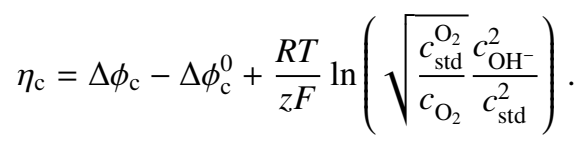

The oxygen reduction overpotential dominates the cell overpotential, but remains almost constant during discharge. This justifies our approach to make use of simple, but consistent global reaction kinetics. More complex rate expressions are discussed elsewhere [46].

The oxygen reduction does not change the surface of the GDE. Our simulations show that almost no $\mathrm{ZnO}$ precipitates in the cathode. Consequently, we assume that the specific surface $A_{\mathrm{IV}}$ remains constant during discharge.

\subsection{3. $\mathrm{ZnO}$ nucleation and growth}

Thermodynamics allows $\mathrm{ZnO}$ to grow for concentrations above the solubility limit $c_{\text {sat }}$ of zincate (see Reaction II). However, nucleation requires greater concentrations [12] and supersaturation ratios up to $s:=c_{\mathrm{Zn}(\mathrm{OH})_{4}} / c_{\text {sat }} \approx 4$ are reported for $\mathrm{Zn}$ anodes [44]. Precipitation is typically diffusion limited for reactions with large supersaturation ratios $s[30,12]$, yielding

$$
j_{\mathrm{II}}=\epsilon_{\mathrm{f}}^{3.5} D_{\mathrm{Zn}(\mathrm{OH})_{4}^{=}} \frac{c_{\mathrm{Zn}(\mathrm{OH})_{4}^{=}}-c_{\mathrm{sat}}}{\delta_{\mathrm{ZnO}}}
$$

with the diffusion layer thickness $\delta_{\mathrm{ZnO}}$. Here we apply the same Bruggemann factor as in Eq. 27. The specific surface area for $\mathrm{ZnO}$ precipitation $A_{\mathrm{II}}$ depends on nucleation and growth of $\mathrm{ZnO}$ particles. This process can be described with classical nucleation theory [12]. We apply a more phenomenological approach to keep the model numerically simple. Nucleation occurs abruptly in our model if the concentration exceeds a critical supersaturation $c_{\text {crit }}$, an additional parameter. The specific surface area is

$$
A_{\mathrm{II}}=\left\{\begin{array}{lc}
4 \pi N_{\mathrm{Zn}} r_{\mathrm{ZnO}}^{2} & c_{\mathrm{Zn}(\mathrm{OH})_{4}^{=}}>c_{\text {crit }} \vee \epsilon_{\mathrm{ZnO}}>\epsilon_{\mathrm{ZnO}}^{0} \\
0 & \text { else. }
\end{array}\right.
$$

To avoid a discontinuity, we linearly ramp up the specific surface area until $100 \mathrm{ZnO}$ monolayers are deposited.

\subsubsection{Oxygen dissolution}

The solubility of oxygen in water (see Reaction III) depends linearly on the partial oxygen pressure via Henry's Law $[45,12]$

$$
c_{\mathrm{O}_{2}}^{*}=10^{-K_{\mathrm{O}_{2}}^{\mathrm{s}}} H_{\mathrm{O}_{2}}^{\mathrm{c}, \mathrm{p}} p_{\mathrm{O}_{2}},
$$

where $H^{\mathrm{c}, \mathrm{p}}$ is Henry's constant and $p_{\mathrm{O}_{2}}$ the partial oxygen pressure. The dependence of solubility on salt concentration, denoted salting out, is described with the Sechenov constant $K^{\mathrm{s}}$ [57].

The kinetics of oxygen dissolution is given by the HertzKnudsen equation [12, 58]

$$
j_{\mathrm{III}}=\frac{p_{\mathrm{O}_{2}} \xi}{c_{\mathrm{O}_{2}}^{*}\left(2 \pi M_{\mathrm{O}_{2}} R T\right)^{0.5}}\left(c_{\mathrm{O}_{2}}^{*}-c_{\mathrm{O}_{2}}\right) .
$$

where $\xi$ denotes the ratio of dissolved molecules to molecules hitting the gas-liquid phase boundary. The specific surface area $A_{\text {III }}$ corresponds to the gas-liquid phase boundary and is assumed constant during the discharge process.

\subsubsection{Carbon dioxide absorption}

Upon absorption, carbon dioxide immediately reacts and forms carbonate (see Reaction V). Due to its high rate, this reaction takes place in a small layer at the gas-liquid phase boundary thinner than the resolution of our 1D model. Therefore, we include a simplified macroscopic pseudo first-order reaction rate in our cell model. In the following, we derive it from a microscopic diffusion-reaction model $[39,59,60]$.

We calculate the concentration of dissolved carbon dioxide in one dimension $(y \in[0, \infty))$ perpendicular to the phase boundary at $y=0$. Diffusion determines its transport since the pressure gradient in the thin surface layer is negligible. Hence, the carbon dioxide concentration fulfills the simple diffusionreaction equation [60]

$$
\partial_{t} c_{\mathrm{CO}_{2}}(y, t)=D_{\mathrm{CO}_{2}} \partial_{y}^{2} c_{\mathrm{CO}_{2}}(y, t)-s_{\mathrm{CO}_{3}^{\prime}}(y, t),
$$

with the rate $s_{\mathrm{CO}_{3}}$ of Reaction $\mathrm{V}$ (see below).

Let us assume that the carbon dioxide concentration remains in equilibrium at the phase boundary. We estimate the solubility $c_{\mathrm{CO}_{2}}^{*}$ for the dissolution of carbon dioxide with Henry's law and find the boundary condition

$$
c_{\mathrm{CO}_{2}}(0, t)=c_{\mathrm{CO}_{2}}^{*}=10^{-K_{\mathrm{CO}_{2}}^{\mathrm{s}}} H_{\mathrm{CO}_{2}}^{\mathrm{c}, \mathrm{p}} p_{\mathrm{CO}_{2}} .
$$


The rate of the microscopic Reaction $\mathrm{V}$ depends linearly on the deviation of the concentration from equilibrium, according to Danckwerts et al. [49]

$$
s_{\mathrm{CO}_{3}^{=}}^{=}=k_{\mathrm{OH}^{-}} c_{\mathrm{OH}^{-}}\left(c_{\mathrm{CO}_{2}}-c_{\mathrm{CO}_{2}}^{\mathrm{eq}}\right) c_{\mathrm{std}}^{-2} \text {. }
$$

Here $k_{\mathrm{OH}^{-}}$denotes the kinetic constant of the rate determining step (see Reaction V.a) for carbon dioxide absorption in alkaline media. The equilibrium concentration $c_{\mathrm{CO}_{2}}^{\mathrm{eq}} \approx 0$ is negligibly small. In the thin film, we assume a constant hydroxide concentration. The simplified local reaction rate yields

$$
s_{\mathrm{CO}_{3}^{=}}^{=}=k_{\mathrm{OH}^{-}} c_{\mathrm{OH}^{-}} c_{\mathrm{CO}_{2}} c_{\mathrm{std}}^{-2} .
$$

On macroscopic time scales, reaction and diffusion through the thin surface layer are fast. Thus, the concentration profile is stationary $c_{\mathrm{CO}_{2}}(0, t)=0$. This simplifies the partial differential equation 34 to the ordinary differential equation

$$
D_{\mathrm{CO}_{3}=} \partial_{x}^{2} c_{\mathrm{CO}_{2}}(y)=k_{\mathrm{OH}^{-}} c_{\mathrm{OH}^{-}} c_{\mathrm{CO}_{2}}(y) c_{\mathrm{std}}^{-2} .
$$

We solve for the concentration profile

$$
c_{\mathrm{CO}_{2}}(y)=c_{\mathrm{CO}_{2}}^{*} \exp \left(-\sqrt{\frac{k_{\mathrm{OH}^{-}} c_{\mathrm{OH}^{-}}}{D_{\mathrm{CO}_{2}} c_{\mathrm{std}}^{2}}} y\right) .
$$

Next, we evaluate the macroscopic reaction rate by integrating the microscopic, local reaction rate $s_{\mathrm{CO}_{3}}=(y)$ and get

$$
\begin{aligned}
j_{\mathrm{V}} & =\int_{0}^{\infty} s_{\mathrm{CO}_{3}^{-}}(y) d y \\
& =c_{\mathrm{CO}_{2}}^{*} \sqrt{k_{\mathrm{OH}^{-}} c_{\mathrm{OH}^{-}} D_{\mathrm{CO}_{2}}} c_{\mathrm{std}}^{-1} .
\end{aligned}
$$

The surface area for oxygen and carbon dioxide absorption $A_{\mathrm{V}}=$ $A_{\text {III }}$ is the gas-liquid phase boundary surface.

\subsection{Electrolyte Convection}

Reactions can change the volume available for electrolyte (see Sec. 3.4) and the electrolyte composition (see Sec. 3.2). For incompressible electrolytes, such volume changes lead to convection. In this section we add convection to the transport theory described in Sec. 3.1 determining transport relative to the center of mass. The convective velocity $\vec{v}$ is defined via the flux of the center of mass motion $\rho:=\sum_{i} M_{i} c_{i}$ [37]

$$
\partial_{t}\left(\epsilon_{\mathrm{e}} \rho\right)=\vec{\nabla} \cdot\left(\epsilon_{\mathrm{e}}^{\beta} \rho \vec{v}_{\mathrm{e}}\right)+\sum_{i} M_{i} S_{i}
$$

We employ this transport equation to calculate the concentration of water in our model.

The convective flux density of each species in the electrolyte is $\vec{N}_{i}^{\text {conv,eff }}=\epsilon_{\mathrm{e}}^{\beta} c_{i} \overrightarrow{\mathrm{v}_{\mathrm{e}}}$. Above we discuss diffusion and migration relative to the center of mass. Therefore, the convective flux density is added to the transport Eqs. 16

$$
\begin{aligned}
& \partial_{t}\left(\epsilon_{\mathrm{e}} c_{i}\right)=\vec{\nabla} \cdot\left(\epsilon_{\mathrm{e}}^{\beta} D_{i} \vec{\nabla} c_{i}\right)+\vec{\nabla} \cdot\left(\epsilon_{\mathrm{e}}^{\beta} \frac{t_{i}}{z_{i} F} \vec{j}\right) \\
&+\vec{\nabla} \cdot\left(\epsilon_{\mathrm{e}}^{\beta} c_{i} \vec{v}_{\mathrm{e}}\right)+S_{i} .
\end{aligned}
$$

Note that convection has no influence on the current density because the electrolyte is locally charge neutral.

Next, we describe how the convective velocity depends on electrolyte composition. Our Ansatz is that the convective velocity is such that the electrolyte equation of state remains fulfilled $[12,13]$. The electrolyte equation of state can be expressed in terms of volumes. This is non-trivial because in general $V_{\text {solution }} \neq V_{\text {solute }}+V_{\text {solvent }}$. The volume change of the solution, caused by adding one more particle of species $i$, is denoted partial molar volume $\bar{V}_{i}$ of species $i$. At constant pressure and temperature it still depends on the composition of the solution [61]. Since the volume is an extensive property, the equation of state is

$$
1=\sum_{i=1}^{k} c_{i} \bar{V}_{i}\left(c_{1}, \ldots, c_{k}\right)
$$

where we parametrize the partial molar volumes $\bar{V}_{i}$ as a function of electrolyte composition in this paper. Together with Eq. 43, we find the following equation for the convective velocity

$$
\vec{\nabla} \cdot\left(\epsilon_{\mathrm{e}}^{\beta} \vec{v}_{\mathrm{e}}\right)=\partial_{t} \epsilon_{\mathrm{e}}-\sum_{i=1}^{k} \bar{V}_{i}\left[S_{i}+\vec{\nabla} \cdot\left(\epsilon_{\mathrm{e}}^{\beta} D_{i} \vec{\nabla} c_{i}\right)+\vec{\nabla} \cdot\left(\epsilon_{\mathrm{e}}^{\beta} \frac{t_{i}}{z_{i} F} \vec{j}\right)\right]
$$

Continuum models of gas diffusion electrodes in fuel cells and metal-air batteries [12, 62] use Darcy's law to connect electrolyte velocity $\vec{v}_{\mathrm{e}}$ and pressure $p_{\mathrm{e}}$ in porous media

$$
\vec{v}_{\mathrm{e}}=-\frac{B_{\mathrm{e}}}{\eta_{\mathrm{e}}} \vec{\nabla} p_{\mathrm{e}}
$$

Here $B_{\mathrm{e}}$ denotes the permeability of the electrodes with respect to the electrolyte and $\eta_{\mathrm{e}}$ the dynamic viscosity of the electrolyte.

\subsection{Solid and Gas Phases}

In this subsection, we describe volume changes due to transport and reactions. The dynamics of the volume fractions of solid phases is determined by the appropriate source terms [45]

$$
\partial_{t} \epsilon_{\mathrm{Zn}}=\bar{V}_{\mathrm{Zn}} S_{\mathrm{Zn}} \quad \text { and } \quad \partial_{t} \epsilon_{\mathrm{ZnO}}=\bar{V}_{\mathrm{ZnO}} S_{\mathrm{ZnO}}
$$

with the constant molar volumes $\bar{V}_{i}$.

In the real button cell, the gas phase is present in a compact void space under the anode lid (see Sec. 2.1) and in the gas diffusion electrode. In our model, we consider this void space to be evenly distributed throughout the anode and the separator and keep the model numerically simple. Due to its large kinematic viscosity, convection of gas is two orders of magnitude faster than convection of electrolyte at the same pressure gradient. Therefore, we assume that the partial pressures $p_{\mathrm{CO}_{2}}$ and $p_{\mathrm{O}_{2}}$ as well as the overall pressure $p_{\mathrm{g}}$ remain constant throughout the cell.

As frequently done for gas diffusion electrodes [12, 13], our model relies on pressure saturation curves which can either be measured or calculated with 3D Lattice-Boltzmann simulations [63]. It is a complex task to lay out the gas diffusion electrode such that it contains an even mixture of electrolyte and gas 
phase. Commercial button cells, however, are well-designed and the specific form of the Leverett J-function does hardly influence our simulation results. Let the saturation $\tilde{s}$ of the porous media be the ratio of the electrolyte volume to the void space $\tilde{s}:=V_{\mathrm{e}} /\left(V_{\mathrm{e}}^{0}+V_{\mathrm{g}}^{0}\right)=\epsilon_{\mathrm{e}} /\left(\epsilon_{\mathrm{e}}^{0}+\epsilon_{\mathrm{g}}^{0}\right)$. Then the saturation is determined by the electrolyte pressure (see Eq. 46) via the Leverett J-function $[12,13]$

$$
J(\tilde{s})=\sqrt{\frac{B_{\mathrm{e}}}{\epsilon_{\mathrm{s}} \sigma^{2}}} p_{\mathrm{c}}:=\sqrt{\frac{B_{\mathrm{e}}}{\epsilon_{\mathrm{s}} \sigma^{2}}}\left(p_{\mathrm{e}}-p_{\mathrm{g}}\right) .
$$

Here $p_{\mathrm{e}}, p_{\mathrm{g}}, p_{\mathrm{c}}$ denote the pressure in the electrolyte, the gas phase, the capillary pressure, respectively. $\sigma$ is the surface tension between electrolyte and GDE and $B_{\mathrm{e}}$ is the GDE permeability for electrolyte.

\subsection{Galvanostatic Condition}

The external current density $i_{\text {cell }}$ must always match the density of exchanged electrons in the electrochemical reactions in each of the electrodes [38]. For the cathode this yields

$$
i_{\text {cell }}=\int_{V_{\mathrm{c}}} z_{\mathrm{IV}} F s_{\mathrm{IV}} d x
$$

Since the electrolyte is modeled charge neutral, it is sufficient to consider this constraint in a single electrode (see Eq. 17).

\section{Parameterization and Computational Details}

\subsection{Parameterization}

We model the Varta PowerOne hearing aid coin cell battery PR44 type p675. Therefore, the parameters represent this battery type. Decades ago, thermodynamics $[64,57,65,66,67$, 68] and ionic transport [69, 70, 71, 72, 39, 30, 73, 74, 64, 73, $34,67,75,76]$ in the aqueous alkaline electrolyte (32 weight percent $\mathrm{KOH}$ ) were accurately studied with experiments. We discuss the parameters in the Supplementary Materials A. Our thermodynamic parameters and transport parameters are based on the extensive literature. In contrast, the reaction kinetics are not known with sufficient accuracy. Therefore, we choose to adjust them such that the simulated discharge curves match the measured ones. Nevertheless, we make sure that the reaction parameters are reasonable by comparing to the literature data $[77,44,32,30,78,12,79]$. We want to highlight that the qualitative features of our simulation results are robust against variations of the kinetic parameters.

\subsection{Computational Details}

For the simulations, we implement our model in Matlab. The finite volume method is used for space discretization [80]. Time evolution is performed by the implicit, Matlab built-in solver ode15i.

\section{Experimental Setup and Procedure}

The electrochemical experiments were carried out with commercial Varta PowerOne hearing aid batteries PR44 Type p675 on a multichannel modular potentiostat/galvanostat VMP3 from Bio-Logic Science Instruments (France). According to the IEC 60086-2 norm, the seal of the cells was removed 10 minutes before starting each experiment, in order to activate the battery.

Afterwards, two different kinds of test were performed on the commercial zinc-air cells:

- Galvanostatic discharge After recording the open circuit voltage (OCV) for 30 seconds, the cells were discharged by applying a constant current ranging from 25 to 125 $\mathrm{Am}^{-2}$. The voltage was monitored over time, until it reached the value of $0.9 \mathrm{~V}$, which was selected as the end of discharge cut-off.

- Lifetime analysis Firstly, in order to reach the voltage plateau, the cells were subject to a galvanostatic discharge step, whose length and current density was selected to be either $5 \mathrm{~h}$ at $100 \mathrm{Am}^{-2}$ or $10 \mathrm{~h}$ at $50 \mathrm{Am}^{-2}$. Afterwards, the cells were left to relax and the OCV recorded for $24 \mathrm{~h}$. After such rest period the cells were partially discharged with a constant current pulse of $100 \mathrm{Am}^{-2}$ or $50 \mathrm{Am}^{-2}$ for 10 minutes. The cell voltage at the end of each pulse was used to monitor the aging of the cell (see Figure B.1 in the Supplementary Materials). Such OCV-pulse pattern was repeated for several days, until the voltage at the end of the pulse dropped to the cut-off value of $0.9 \mathrm{~V}$.

The tests were performed at room temperature and atmosphere if not stated otherwise. Therefore, small fluctuations in the discharge voltage profiles can be addressed to uncontrollable environmental changes in the laboratory over the experiment timespan.

In order to ensure the reproducibility of the experimental results, each kind of test was repeated at least once. Despite small variation due to uncontrollable factors (e.g., air flow in the laboratory, temperature fluctuation, and eventual differences among the cells coming from the factory), the qualitative features necessary to validate the modeling was always observed. For sake of brevity, we report the most representative measurements only.

\section{Galvanostatic Discharge}

In this section, we discuss the discharge of the zinc-air button cell at various currents. Our simulations allow to study internal variables like ion concentrations and phase distributions which are not directly accessible experimentally. Therefore, we interpret the experimental and theoretical discharge curves by analyzing the simulated internal variables in parallel. The procedure for experiment and simulation is described in detail in Sec. 5 . 

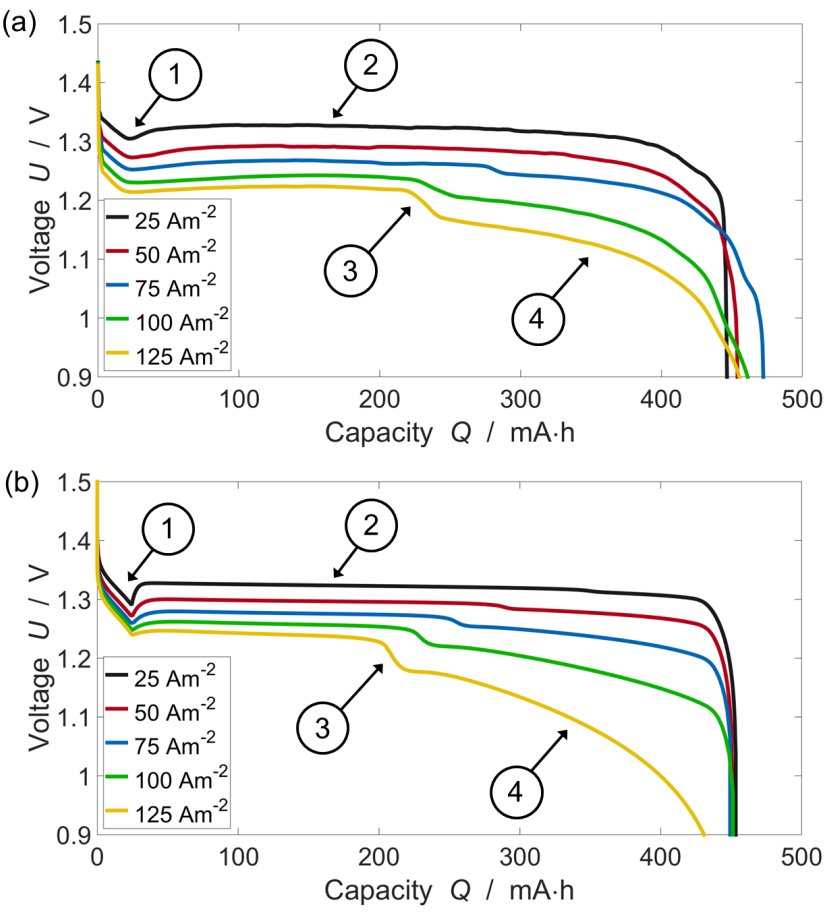

Figure 3. (a) Experimentally measured and (b) simulated cell voltage profiles during galvanostatic discharge at various current densities. The four key features in the voltage curves are marked with numbers and discussed in the text 1) initial voltage dip, 2) voltage plateau, 3) voltage step, 4) voltage decay.

\subsection{Experiment}

Discharge profiles at various current densities are plotted in Fig. 3. The voltage generally decreases with increasing discharge current. We observe four characteristic features in each discharge curve:

1. At the beginning of the discharge process, the voltage drops rapidly until a minimum is reached. Then the voltage recovers slightly. This feature occurs at the same discharged capacity regardless of the current.

2. After the initial dip, the cell voltage remains nearly constant for more than half of the discharge time. This plateau is wider at smaller discharge currents.

3. At the end of the voltage plateau, the voltage drops rapidly This voltage step is larger at higher currents and most pronounced at $i=125 \mathrm{Am}^{-2}$. At the smallest current density $i=25 \mathrm{Am}^{-2}$, it is hardly recognizable.

4. After the voltage step, the cell voltage decreases, until it reaches the cut-off voltage.

\subsection{Simulation}

The simulated discharge curves at various currents are depicted in Fig. 3b. We observe the same four characteristics in the simulated discharge profiles as in the experiments (see Sec. 6.1). After a pronounced dip, the voltage remains constant during most of the discharge. The voltage plateau ends with a deep voltage step. Position and magnitude of the step depend on the applied current. Finally, the voltage drops and approaches the cut-off voltage.
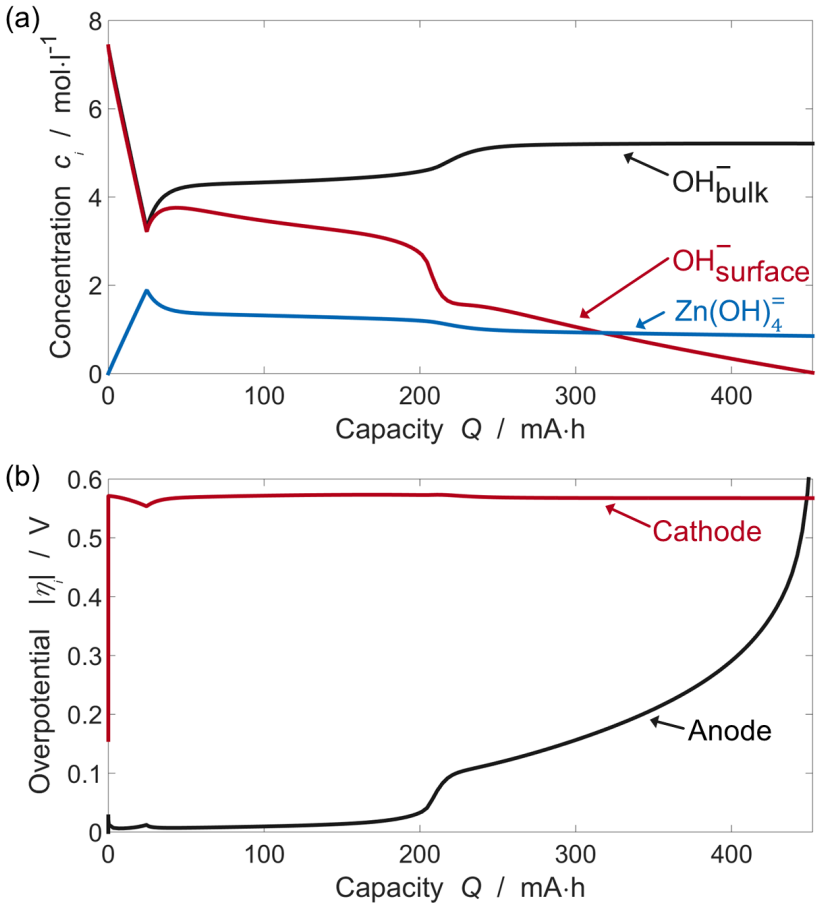

Figure 4. (a) Mean concentration of hydroxide and zincate in the anode during galvanostatic discharge at $125 \mathrm{Am}^{-2}$. The zincate concentration rises until the critical supersaturation is reached consuming more hydroxide than replaced by oxygen reduction. Then $\mathrm{ZnO}$ nucleates and precipitation starts. In the following, the concentration of zincate decreases slowly due to the growing active surface area of the precipitation reaction. Accordingly, the bulk hydroxide concentration increases again. The hydroxide concentration at the $\mathrm{Zn}$ surface is dropping at the end of discharge due to the diffusion through the $\mathrm{ZnO}$ shell. (b) Overpotentials during galvanostatic discharge at $125 \mathrm{Am}^{-2}$. The high cathodic overpotential remains nearly constant during the discharge process. It is the origin of the initial activation overpotential in the voltage profile (see Fig. 3b) and thereby the plateau voltage. The final growth of the anodic overpotential originates from the loss of hydroxide concentration at the $\mathrm{Zn}$ surface (see Fig. 4a) and determines the drop in the cell voltage profile.

\subsubsection{Voltage dip}

First, we discuss the initial voltage dip for the discharge current $i=125 \mathrm{Am}^{-2}$. Activation of the slow oxygen reduction leads to a sharp instantaneous voltage drop from the OCV. The voltage dip is a signature for the nucleation of $\mathrm{ZnO}$. We illustrate this based on the mean ion concentrations in the anode (see Fig. 4a).

Fig. $4 \mathrm{a}$ depicts the mean concentrations of hydroxide and zincate ions. Initially, the zincate concentration increases linearly, while the hydroxide concentration decreases linearly. Subsequently, the zincate concentration decreases slightly, while the hydroxide concentration increases. Then the hydroxide concentration at the $\mathrm{Zn}$ surface decreases, while the bulk hydroxide concentration increases.

During $\mathrm{Zn}$ oxidation, hydroxide is consumed and zincate is formed. This explains the initial linear increase in zincate concentration and the decrease in hydroxide concentration. A lower hydroxide and a higher zincate concentration result in a larger overpotential in the anode. When the critical supersaturation is reached, $\mathrm{ZnO}$ starts to nucleate and zincate precipitates as $\mathrm{ZnO}$. With increasing area for precipitation, the zincate con- 
centration decreases and the hydroxide concentration increases. This results in an increase in cell voltage. We will explain the final drop in hydroxide concentration at the $\mathrm{Zn}$ surface with the diffusion through $\mathrm{ZnO}$ below and correlate it to the cell potential.

\subsubsection{Voltage plateau}

After the nucleation of $\mathrm{ZnO}$, the battery discharges in a quasi-stationary regime as expected for conversion reactions. Only the amounts of $\mathrm{Zn}$ and $\mathrm{ZnO}$ change and affect the surface areas in the anode. This stationary regime is clearly demonstrated by the cathodic and anodic overpotentials during discharge shown in Fig. 4b. The instant reaction activation overpotentials are very pronounced. The cathodic overpotential dominates and remains constant throughout the full discharge. In the plateau region, the anodic overpotential increases slightly before it rapidly increases after the voltage step. This final increase is due to the diffusion limitation through $\mathrm{ZnO}$ (see below).

\subsubsection{Voltage step and decay}

At the end of the plateau region, a step in cell voltage occurs. Such behavior is typically interpreted with a change in reaction mechanism. The insights from our simulation show, however, that the voltage step originates from the inhomogeneous nucleation of $\mathrm{ZnO}$.

To explain this mechanism, we plot the volume fractions of all phases in the button cell in Fig. 5. We observe that $\mathrm{ZnO}$ does not nucleate next to the separator, but precipitates next to the current collector. There a $\mathrm{ZnO}$ film passivates the $\mathrm{Zn}$ and limits its dissolution. Thus, during the voltage plateau the uncovered $\mathrm{Zn}$ close to the separator is preferentially dissolved. When the voltage step is reached, this uncovered $\mathrm{Zn}$ is completely gone (see Fig. 5c). The remaining $\mathrm{Zn}$ is already covered with a thick $\mathrm{ZnO}$ film. After the voltage drop, the $\mathrm{Zn}$ beneath this thick film takes over and its oxidation becomes responsible for the cell current. These observations explain the voltage step. It results from the sudden change from the oxidation of uncovered to covered $\mathrm{Zn}$ that requires a jump in the driving force for oxidation.

We highlight the importance of electrolyte management based on Fig. 5. Initially, a huge void space filled with gas is present throughout the anode. This is a model representation of the gas space on top of the anode in the real button cell. During discharge the solid volume fraction increases as $\mathrm{Zn}$ is converted into $\mathrm{ZnO}$. The void space ensures that the electrolyte is not leaking out of the gas diffusion electrode. This void space just stays open at the end-of-discharge demonstrating that this VARTA button cell is well optimized. In conclusion, we find that the electrolytic parameters remain stable during battery discharge and charge. Furthermore, a well optimized gas diffusion electrode guarantees stable oxygen concentrations throughout the cell at these relatively low current densities, as shown previously [12].

Next, we want to understand the origin of this inhomogeneous precipitation from the concentration profiles depicted in
Fig. 6. It shows hydroxide concentration at the electrode surface and in the bulk together with zincate concentration. Note that the potassium concentration is the sum over these anionic concentrations. We observe that the hydroxide concentration is increasing towards the cathode whereas the zincate concentration is maximal in the anode close to the separator. At the voltage dip, the rising zincate concentration surpasses the supercritical concentration next to the current collector where potassium concentration and zincate solubility are lowest (see Supplementary Materials A1.2). Next to the separator, potassium concentration and solubility are higher and do not allow $\mathrm{ZnO}$ nucleation.

During further discharge, the concentration of hydroxide at the $\mathrm{Zn}$ surface is decreasing in the presence of the $\mathrm{ZnO}$ film (see 6d and Fig. 4a). This causes the final cell voltage loss and increase in anode overpotential at $125 \mathrm{Am}^{-2}$. The $\mathrm{ZnO}$ film is growing during discharge and acts as a diffusion barrier for hydroxide (see Eq. 27).

\subsubsection{Discharge currents}

In this section, we compare the simulated discharge curves for various current densities (see Fig. 3b). It is clear that reaction rates, transport rates, and thus the overpotential depend on the discharge current. Higher currents generally result in higher overpotentials. In Fig. 3b, on closer examination it is found that only the discharge curve at $125 \mathrm{Am}^{-2}$ shows the typical shape for diffusion limitations. We find in our simulations that the discharge at lower currents is limited by the total $\mathrm{Zn}$ amount in the anode.

The voltage step is an important finding of this paper. The discharged capacity at which this step occurs decreases with increasing discharge current. This can be explained by comparing the profiles of the specific active surface areas for $\mathrm{ZnO}$ precipitation in Fig. 7a. The active surface areas increase from current collector to separator in the anode. Next to the separator, no surface area is available. This region increases with increasing discharge current.

The increase in surface area from the current collector to the separator shows that $\mathrm{ZnO}$ growth is preferred close to the separator and leads to larger $\mathrm{ZnO}$ shells. The absence of surface area next to the separator is explained above via inhomogeneous nucleation. A faster discharge leads to a larger overshoot of the zincate concentration above the supercritical limit, which increases the nucleated surface. Thus, the region without $\mathrm{ZnO}$ is smaller and the voltage step is observed at a lower discharged capacity.

\subsubsection{Battery cycling}

The implications of our analysis for the development of rechargeable zinc-air batteries are demonstrated by simulating one recharge after a full discharge to the fixed capacity $Q=$ $407 \mathrm{mAh}$ or the voltage cut-off $U=1.1 \mathrm{~V}$ (see Supplementary Materials D). We consider two scenarios: First, we prepare a pure $\mathrm{Zn}$ anode; second, we admix 2 volume percent $\mathrm{ZnO}$. In the latter case the voltage dip during discharge disappears. This is because the admixture of $\mathrm{ZnO}$ makes its nucleation need- 

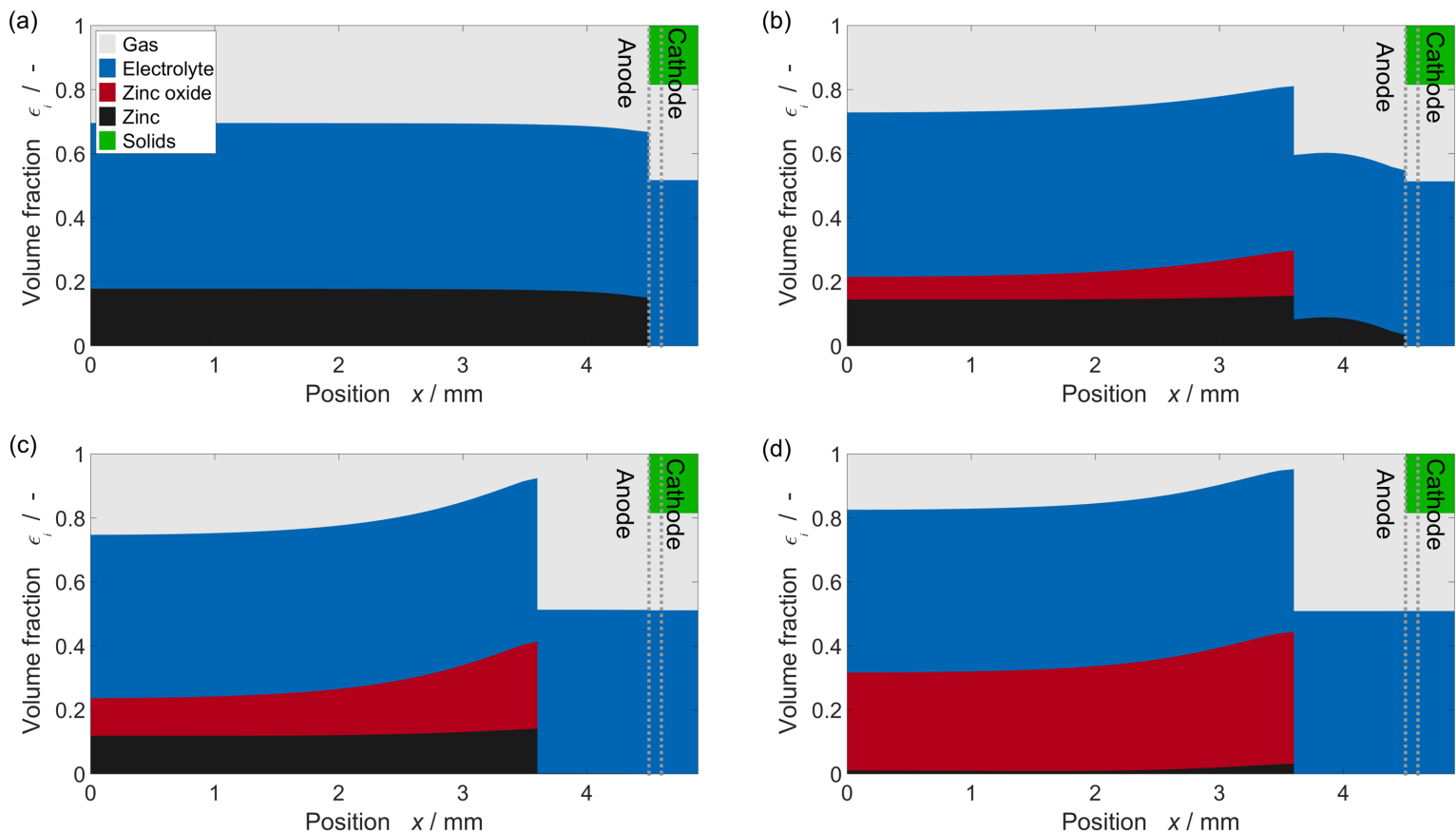

Figure 5. Volume fractions during galvanostatic discharge at $125 \mathrm{Am}^{-2}$ at characteristic times (see Fig. 3): (a) Dip: No ZnO is precipitating. Zn dissolves slightly faster next to the separator. (b) Plateau: $\mathrm{ZnO}$ nucleated and precipitating in the part of the anode close to the current collector (see Fig. 6). Zn dissolution is slowed down in the presence of $\mathrm{ZnO}$. (c) Step: $\mathrm{Zn}$ is completely dissolved in the part of the anode in which no $\mathrm{ZnO}$ is nucleated. (d) Drop: A thick $\mathrm{ZnO}$ film slows down the dissolution of the remaining $\mathrm{Zn}$.
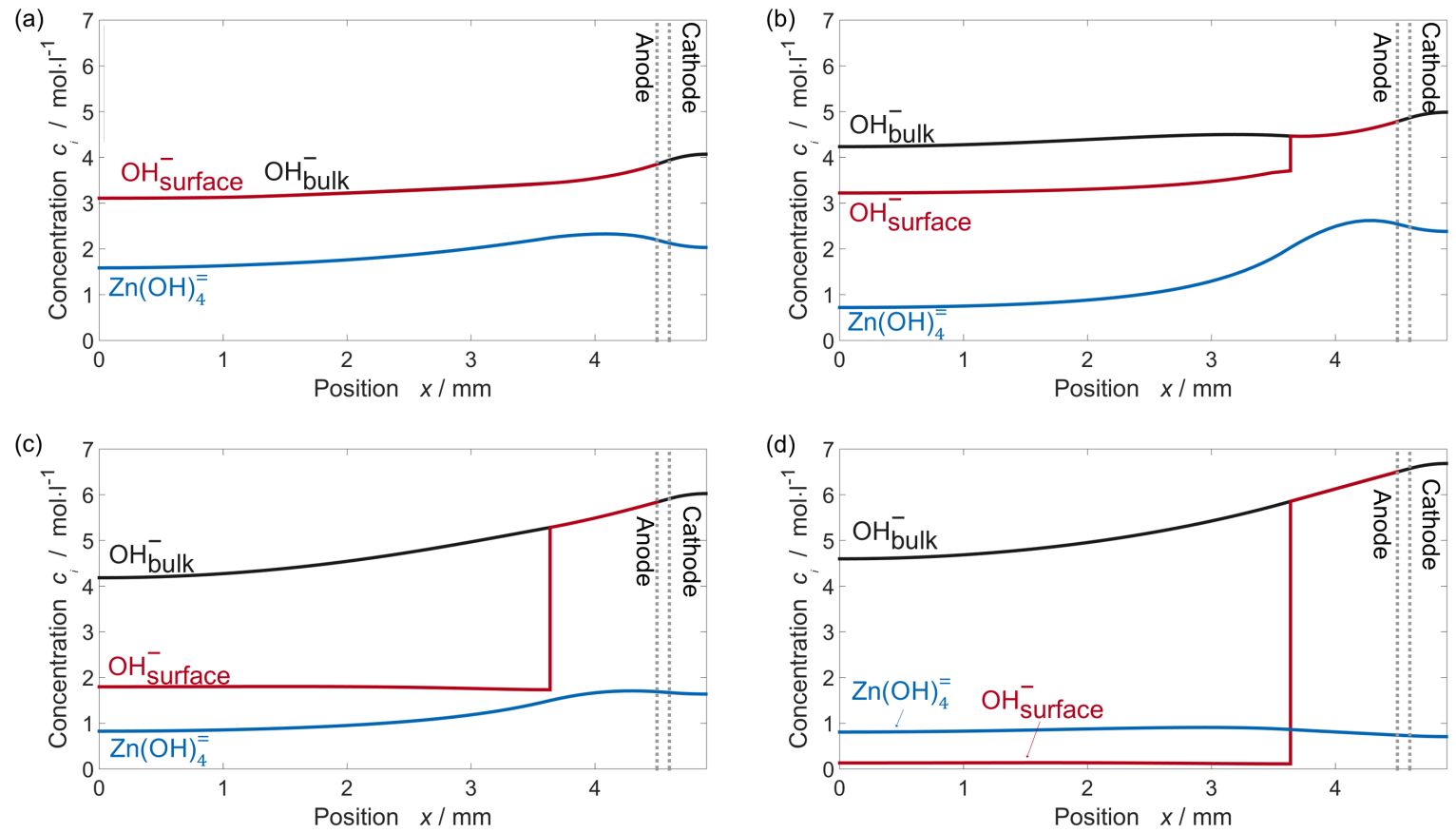

Figure 6. Various concentration profiles during galvanostatic discharge at $125 \mathrm{Am}^{-2}$ at characteristic times (see Fig. 3): (a) Dip: Zincate concentration is maximum. Critical supersaturation is reached next to the current collector, where zincate solubility is low due to low potassium concentration. (b) Plateau, and (c) Step: Hydroxide bulk concentration and zincate concentration remain nearly constant. Hydroxide surface concentration decreases in parts of the anode due to growing $\mathrm{ZnO}$ film. (d) Drop: Hydroxide concentration at the $\mathrm{Zn}$ surface is small and limits $\mathrm{Zn}$ dissolution. 

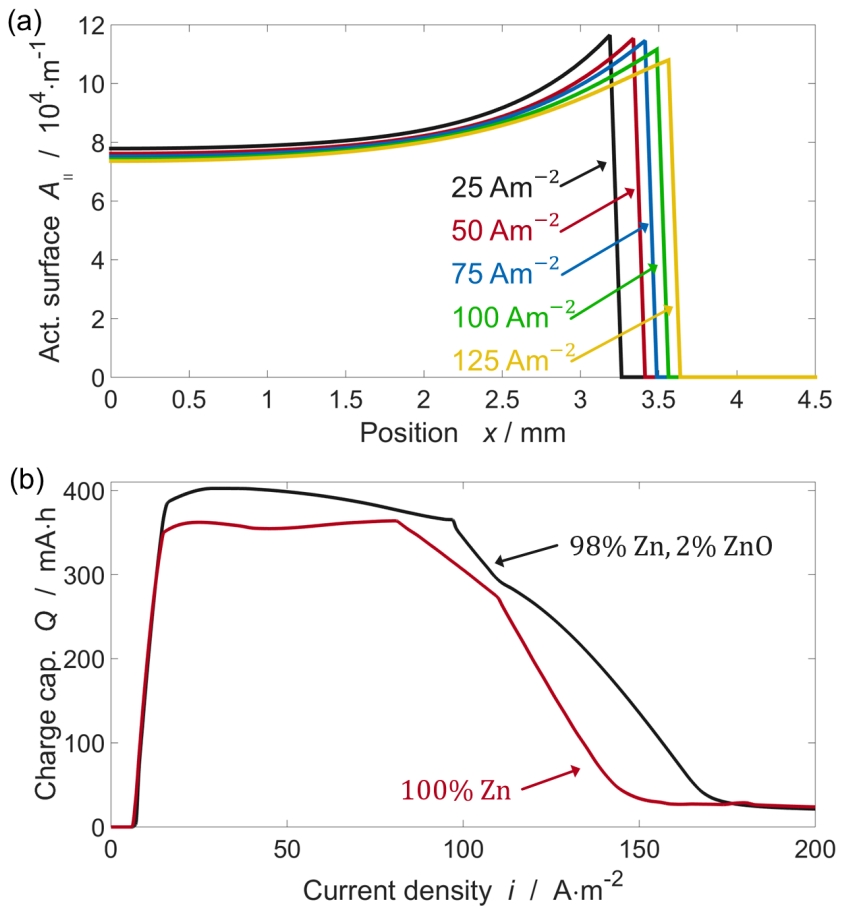

Figure 7. (a) Active surface for $\mathrm{ZnO}$ precipitation during galvanostatic discharge at various current densities. For higher current densities the region where no $\mathrm{ZnO}$ precipitates is smaller. Therefore, the capacity at which all $\mathrm{Zn}$ is dissolved in this region is smaller for higher currents and the voltage step occurs at lower capacities. (b) Rechargeable capacity after discharge to $Q=407 \mathrm{mAh}$ ( $90 \%$ capacity) or $U=1.1 \mathrm{~V}$. By mixing $\mathrm{ZnO}$ into the $\mathrm{Zn}$ anode, the rechargeable capacity increases.

less and guarantees more homogeneous deposition of $\mathrm{ZnO}$. As a consequence, $\mathrm{Zn}$ dissolves more homogeneously.

We compare the corresponding rechargeable capacities in Fig. 7b. Let us explain the different regimes for the example of a pure $\mathrm{Zn}$ anode. At very low current densities $i \lesssim 15 \mathrm{Am}^{-2}$, $\mathrm{CO}_{2}$ absorption limits the capacity. At intermediate current densities $15 \mathrm{Am}^{-2} \lesssim i \lesssim 80 \mathrm{Am}^{-2}$, the rechargeable capacity remains almost constant because it is limited by the amount of accessible $\mathrm{ZnO}$. At $80 \mathrm{Am}^{-2} \lesssim i \lesssim 110 \mathrm{Am}^{-2}$, dissolution of $\mathrm{ZnO}$ is capacity limiting even though $\mathrm{ZnO}$ remains available in the anode. Above $i \gtrsim 110 \mathrm{Am}^{-2}$, discharge capacity is limiting. We observe that the admixture of $\mathrm{ZnO}$ increases the rechargeable capacity because $\mathrm{ZnO}$ and $\mathrm{Zn}$ remain evenly distributed. This effect is most pronounced at relatively low currents where the surface area for $\mathrm{ZnO}$ dissolution is capacity limiting. To conclude, admixture of $\mathrm{ZnO}$ leads to more homogeneous precipitation/dissolution and increases the rechargeable capacity of zinc-air batteries.

\subsection{Validation and Discussion}

Finally, we compare measured (see Fig. 3a) and simulated discharge (see Fig. 3b). Note that this paper highlights the qualitative agreement of our theory-based continuum modeling with electrochemical measurements and gives novel insight based on simulations. Excellent quantitative agreement, which is not the aim of this paper, could be gained by adding more parameters and performing extensive parameter adjustments. Nevertheless, we discuss potential model refinements in the following. The four characteristic features, i.e., voltage dip, voltage plateau, voltage step, and voltage drop, are found in both, theory and experiment.

Around the voltage dip, the cell potentials do not exactly agree. Activity coefficients are not included in our modeling, but would affect the cell potential when the zincate concentrations is supercritical at the voltage dip. The increase of the voltage after the dip is very sharp in our simulations. This might be a result of our mean-field description of the nucleation process assuming that nucleation happens in one burst. In reality, small islands might nucleate, grow, and merge to form closed $\mathrm{ZnO}$ shells. In this case of agglomeration, the specific surface area for $\mathrm{ZnO}$ precipitation would approach full coverage more continuously. This effect would lead to a slower increase in cell voltage.

Magnitude and position of the voltage step agrees very well between model and measurement. At small current densities the voltage step is barely visible in the measured discharge curves, whereas it can still be observed in the simulation. This is a consequence of the lower noise level in the simulations. This excellent agreement supports our interpretation that the voltage dip signals inhomogeneous nucleation. In secondary zinc-air cells it would be advantageous to precipitate $\mathrm{ZnO}$ and dissolve Zn homogeneously. This can be achieved by preparing the anode as a mix of $\mathrm{ZnO}$ and $\mathrm{Zn}$. The added $\mathrm{ZnO}$ will act as nucleation seed for precipitation. This method will reduce the initial discharge capacity, but improve the cycle life of the $\mathrm{Zn}$ anode.

The final diffusion limited voltage drop represents a significant shortcoming of our model. In simulations, the diffusion limited regime is only found at $125 \mathrm{Am}^{-2}$, whereas in experiments, it seems to occur at smaller currents, too. It is interesting that the measurements show a non-monotonous dependence of total discharge capacity on cell current. Furthermore, this behavior at the end of discharge is not exactly reproducible in our experiments. This indicates that the end of discharge is influenced by degradation. Degradation strongly depends on lab conditions, e.g., moisture, temperature. Examples of degradation mechanisms are hydrogen evolution, corrosion of the current collectors, and formation of type II $\mathrm{Zn}$. Type II $\mathrm{Zn}$ is not contained in our model but would create an additional diffusion barrier at low enough voltages $U \lesssim 1.1 \mathrm{~V}$ at the end of discharge [52]. Also, taking into account a $\mathrm{Zn}$ radius distribution would result in a smoother decay of $\mathrm{Zn}$ surface area at the end of discharge and a smoother decay in cell voltage as observed in our measurements $[12,81]$. We capture diffusion limitations at the end of discharge by the simplified rate Eqs. 27 and 30 for $\mathrm{Zn}$ dissolution and $\mathrm{ZnO}$ precipitation and propose microscopic modeling of electrolyte transport around individual $\mathrm{Zn}$ particles.

\section{Lifetime Analysis}

We study the lifetime of the zinc-air button cell (see Sec. 5 for measurement sequence) in this section. To this aim, we perform experiments and simulations giving insights into the 
(a)

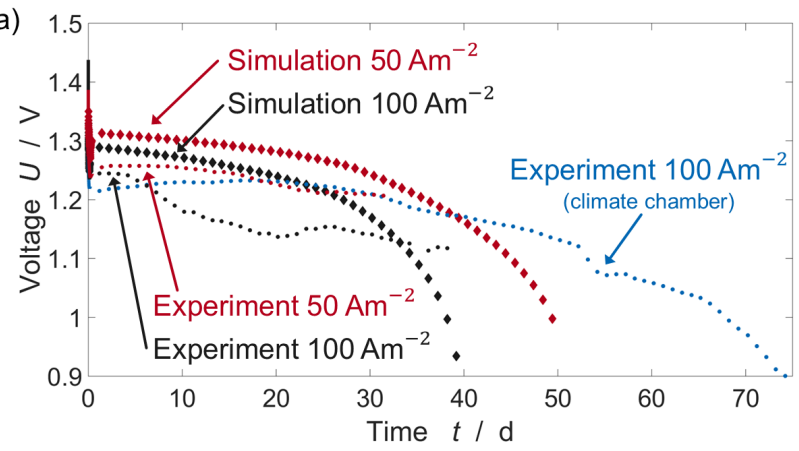

(b)

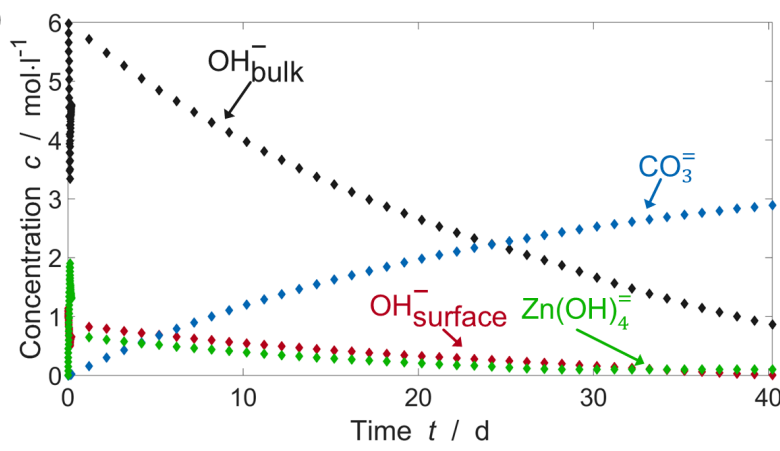

Figure 8. Lifetime analysis at $50 \mathrm{Am}^{-2}$ (red) and $100 \mathrm{Am}^{-2}$ (black) (a) Cell voltage profile in lifetime experiment (diamonds) and simulation (dots). One experiment (blue) is carried out in the climate chamber at $20^{\circ} \mathrm{C}$, while the other experiments are performed at room temperature and at lab atmosphere. The initial voltage drop is caused by the $5 \mathrm{~h}$ galvanostatic discharge. Thereafter, the cell voltage decreases linearly over time. The decrease is independent from the current density. At the end of battery lifetime, faster voltage decay occurs. (b) Mean concentrations of various ions during lifetime experiment at $100 \mathrm{Am}^{-2}$. The hydroxide concentration $c_{\mathrm{OH}^{-}}$is decreasing due to carbonate $c_{\mathrm{CO}_{3}}$ absorption. This reduces the zincate solubility/concentration $c_{\mathrm{Zn}(\mathrm{OH})_{4}}$. The reduction of hydroxide concentration slows down further $\mathrm{Zn}$ dissolution and limits the cell lifetime.

underlying degradation process. Our measurement procedure is described in detail in Sec. 6.1. First, we prepare the cell through a continuous discharge and let $\mathrm{ZnO}$ nucleate. Every following day we measure the steady-state voltage for the current densities $100 \mathrm{Am}^{-2}$ or $50 \mathrm{Am}^{-2}$. When the cut-off voltage of $0.9 \mathrm{~V}$ is reached, we finish our measurement. The measured voltage as a function of time is shown in the Supplemental Materials in in Fig. B.1.

Various aging profiles are plotted in Fig. 8a. During the daily measurements, the voltages increase slightly for around 10 days before starting to decrease slowly. Accelerated voltage decay and cell failure occur after one to two months. The voltage profiles are not reproducible and contain a significant amount of noise. In contrast, during short galvanostatic discharge, the voltages are well reproducible. We attribute this noise to the fluctuating environmental conditions in our lab, e.g., temperature, pressure, and air composition. A reference measurement in a climate chamber yields smoother results, even though the air composition is not controlled.

Lifetime simulations are depicted in Fig. 8a. The voltage is decreasing within a day in our simulations before decreasing logarithmically. The lifetime is limited to 40 days. We study the origin of cell failure by plotting mean ion concentrations in Fig. 8b. The absorption of carbon dioxide and formation of carbonate leads to an almost linear increase in carbonate concentration (see Reaction V). Because this carbonate formation consumes hydroxide, the hydroxide concentration in the electrolyte is reduced significantly. A low hydroxide concentration results in low zincate solubility. The battery cell finally fails due to this decrease in hydroxide concentration and zincate solubility which slow down the further dissolution of $\mathrm{Zn}$. Note that this mechanism does not involve the precipitation of solid carbonates as shown for alkaline electrolytes before [36]. Instead, the reduction in $\mathrm{pH}$ is the major consequence of carbon dioxide absorption and the cause for cell failure.

A strategy for mitigating carbon dioxide absorption is illustrated in the Supplementary Materials C. We simulate how a decrease in carbon dioxide content in the feed gas extends the lifetime. Drillet et al. analyze the use of carbon dioxide filters to this aim [24].

We now compare the simulated voltage profile with the measured one (see Fig. 8a). Generally, the simulated voltages are $50 \mathrm{mV}$ too large. This deviation is less distinct during galvanostatic discharge (see Sec. 6). It stems from the relaxation in zincate and hydroxide concentration during battery storage. Agreement would be improved by substituting the global electrochemical kinetics (see Eqs. 22,28) with adjusted expressions $[30,43,56]$ that weaken the dependence of reaction kinetics on ionic concentrations. The good agreement in the voltage slope and the lifetime shows that our simulations qualitatively capture the lifetime limitation. This level of agreement is reached by using a relatively small surface area for carbonate formation, which is two orders of magnitude smaller than expected. Previous studies show a shorter battery lifetime [24, 25] of around 10 days. Therefore, we hypothesize that the measured VARTA button cell is optimized to reduce carbon dioxide absorption.

\section{Conclusion}

Zinc-air batteries were proposed as promising candidates for stationary energy storage due to the use of abundant materials. In this article, we model the discharge of a commercial zinc-air button cell and validate it with experiments. Our simulations describe electrolyte convection and take into account nucleation and growth of the discharge product. We find that the primary zinc-air battery exhibits inhomogeneous deposition and dissolution of $\mathrm{ZnO}$ and $\mathrm{Zn}$. Adding $\mathrm{ZnO}$ to the zinc anode is shown to improve the rechargeable capacity even though it reduces the initial discharge capacity. Additionally, we show that battery lifetime is limited by carbon dioxide absorption into the aqueous alkaline electrolyte. This effect can be mitigated by using carbon dioxide filters or employing neutral electrolytes.

\section{Acknowledgement}

The authors thank Martin Krebs (VARTA Microbattery) and Simon Clark for fruitful discussions. We acknowledge financial support by the EU commission through the project ZAS! ZincAir Secondary (Grant Agreement 646186). Further support was 
provided, by the bwHPC initiative and the bwHPCC5 project through associated compute services of the JUSTUS HPC facility at the University of Ulm.

\section{References}

[1] Y. Li, H. Dai, Recent advances in zinc air batteries, Chem. Soc. Rev. 43 (15) (2014) 5257-5275. doi:10.1039/C4CS00015C. 136, 137

[2] L. Grande, E. Paillard, J. Hassoun, J. B. Park, Y. J. Lee, Y. K. Sun, S. Passerini, B. Scrosati, The lithium/air battery: Still an emerging system or a practical reality?, Advanced Materials 27 (2015) 784-800. doi:10.1002/adma.201403064. 136

[3] N. B. Aetukuri, B. D. McCloskey, J. M. García, L. E. Krupp, V. Viswanathan, A. C. Luntz, Solvating additives drive solution-mediated electrochemistry and enhance toroid growth in non-aqueous $\mathrm{LiO} 2$ batteries, Nature Chemistry 7 (January) (2015) 50-56. doi : 10.1038/nchem . 2132. 136

[4] L. Johnson, C. Li, Z. Liu, Y. Chen, S. A. Freunberger, P. C. Ashok, B. B. Praveen, K. Dholakia, J.-M. Tarascon, P. G. Bruce, The role of $\mathrm{LiO} 2$ solubility in $\mathrm{O} 2$ reduction in aprotic solvents and its consequences for LiO2 batteries, Nature Chemistry 6 (12) (2014) 1091-1099. doi: 10.1038/nchem. 2101. 136

[5] T. Liu, M. Leskes, W. Yu, A. J. Moore, L. Zhou, P. M. Bayley, G. Kim, C. P. Grey, Y. Wanjing, A. J. Moore, L. Zhou, P. M. Bayley, G. Kim, C. P. Grey, Cycling Li-O2 batteries via $\mathrm{LiOH}$ formation and decomposition, Science 350 (6260) (2015) 530-533. doi:10.1126/science. aac7730. 136

[6] J. Lu, Y. Jung Lee, X. Luo, K. Chun Lau, M. Asadi, H.-H. Wang, S. Brombosz, J. Wen, D. Zhai, Z. Chen, D. J. Miller, Y. Sub Jeong, J.-B. Park, Z. Zak Fang, B. Kumar, A. Salehi-Khojin, Y.-K. Sun, L. A. Curtiss, K. Amine, A lithium oxygen battery based on lithium superoxide, Nature 529 (7586) (2016) 1-7. doi:10.1038/nature16484. 136

[7] X. Gao, Y. Chen, L. Johnson, P. G. Bruce, Promoting solution phase discharge in $\mathrm{LiO} 2$ batteries containing weakly solvating electrolyte solutions, Nature Materials 15 (2016) 882-888. doi : 10.1038/nmat4629. 136

[8] K. U. Schwenke, M. Metzger, T. Restle, M. Piana, H. A. Gasteiger, The Influence of Water and Protons on Li2O2 Crystal Growth in Aprotic LiO2 Cells, Journal of The Electrochemical Society 162 (4) (2015) A573A584. doi:10.1149/2.0201504jes. 136

[9] B. Horstmann, B. Gallant, R. Mitchell, W. G. Bessler, Y. Shao-Horn, M. Z. Bazant, Rate-Dependent Morphology of Li2O2 Growth in Li-O2 Batteries, The Journal of Physical Chemistry Letters 4 (24) (2013) 4217 4222. doi:10.1021/jz401973c. 136

[10] P. Stevens, G. Toussaint, G. Caillon, P. Viaud, P. Vinatier, C. Cantau, O. Fichet, C. Sarrazin, M. Mallouki, Development of a lithium air rechargeable battery, in: ECS Transactions, Vol. 28, 2010, pp. 1-12. doi:10.1149/1.3507922. 136

[11] T. Zhang, N. Imanishi, Y. Takeda, O. Yamamoto, Aqueous Lithium/Air Rechargeable Batteries, Chemistry Letters 40 (7) (2011) 668-673. doi : 10.1246/cl.2011.668. 136

[12] B. Horstmann, T. Danner, W. G. Bessler, Precipitation in aqueous lithium oxygen batteries: a model-based analysis, Energy \& Environmental Science 6 (4) (2013) 1299. doi:10.1039/c3ee24299d. 136, 137, 141, $142,143,145,147$

[13] T. Danner, B. Horstmann, D. Wittmaier, N. Wagner, W. G. Bessler, Reaction and transport in $\mathrm{Ag} / \mathrm{Ag} 2 \mathrm{O}$ gas diffusion electrodes of aqueous $\mathrm{Li}-\mathrm{O} 2$ batteries: Experiments and modeling, The Journal of Power Sources 264 (2014) 320-332. doi : 10.1016/j . jpowsour. 2014.03.149. 136, 137, 142,143

[14] P. Adelhelm, P. Hartmann, C. L. Bender, M. Busche, C. Eufinger, J. Janek, From lithium to sodium: Cell chemistry of room temperature sodium-air and sodium-sulfur batteries, Beilstein Journal of Nanotechnology 6 (1) (2015) 1016-1055. doi : 10.3762/bjnano.6.105. 137

[15] P. Hartmann, C. L. Bender, M. Vračar, A. K. Dürr, A. Garsuch, J. Janek, P. Adelhelm, A rechargeable room-temperature sodium superoxide (NaO2) battery, Nature Materials 12 (3) (2012) 228-232. doi : 10.1038/nmat3486. 137

[16] J. Kim, H. Park, B. Lee, W. M. Seong, H.-D. Lim, Y. Bae, H. Kim, W. K. Kim, K. H. Ryu, K. Kang, Dissolution and ionization of sodium superox- ide in sodium oxygen batteries, Nature Communications 7 (2016) 10670. doi:10.1038/ncomms10670. 137

[17] M. Xu, D. Ivey, Z. Xie, W. Qu, Rechargeable Zn-air batteries: Progress in electrolyte development and cell configuration advancement, Journal of Power Sources 283 (2015) 358-371. doi:10.1016/j.jpowsour. 2015.02.114. 137

[18] K. Harting, U. Kunz, T. Turek, Zinc-air Batteries: Prospects and Challenges for Future Improvement, Zeitschrift für Physikalische Chemie 226 (2) (2012) 151-166. 137

[19] Y. Li, M. Gong, Y. Liang, J. Feng, J. E. Kim, H. Wang, G. Hong, B. Zhang, H. Dai, Advanced zinc-air batteries based on high-performance hybrid electrocatalysts, Nature Communications 4 (1805) (2013) 1-7. doi:10.1038/ncomms2812. 137

[20] V. Neburchilov, H. Wang, J. J. Martin, W. Qu, A review on air cathodes for zinc-air fuel cells, Journal of Power Sources 195 (5) (2010) 1271-1291. doi:10.1016/j.jpowsour.2009.08.100.137, 138

[21] F. R. McLarnon, E. J. Cairns, The Secondary Alkaline Zinc Electrode, Journal of The Electrochemical Society 138 (2) (1991) 645. doi:10. 1149/1.2085653. 137

[22] O. Gröger, H. A. Gasteiger, J.-P. Suchsland, Review Electromobility: Batteries or Fuel Cells?, Journal of The Electrochemical Society 162 (14) (2015) A2605-A2622. doi : 10.1149/2.0211514jes. 137

[23] J.-S. J.-S. Lee, S. Tai Kim, R. Cao, N.-S. N.-S. Choi, M. Liu, K. T. Lee, J. Cho, Metal-Air Batteries with High Energy Density: Li-Air versus ZnAir, Advanced Energy Materials 1 (1) (2011) 34-50. doi:10.1002/ aenm. 201000010. 137

[24] J.-F. Drillet, F. Holzer, T. Kallis, S. Müller, V. M. Schmidt, Influence of $\mathrm{CO} 2$ on the stability of bifunctional oxygen electrodes for rechargeable zinc/air batteries and study of different CO2 filter materials, Physical Chemistry Chemical Physics 3 (3) (2001) 368-371. doi:10.1039/ b005523i. 137, 138, 148

[25] D. Schröder, U. Krewer, Model based quantification of air-composition impact on secondary zinc air batteries, Electrochimica Acta 117 (2014) 541-553. doi:10.1016/j.electacta.2013.11.116. 137, 140, 148

[26] D. A. Cogswell, Quantitative phase-field modeling of dendritic electrodeposition, Physical Review E 92 (1) (2015) 011301. doi:10.1103/ PhysRevE.83.061602. 137

[27] T. Arlt, D. Schröder, U. Krewer, I. Manke, In operando monitoring of the state of charge and species distribution in zinc air batteries using Xray tomography and model-based simulations, Phys. Chem. Chem. Phys. 16 (40) (2014) 22273-22280. doi:10.1039/C4CP02878C. 137

[28] F. W. Thomas Goh, Z. Liu, T. S. A. Hor, J. Zhang, X. Ge, Y. Zong, A. Yu, W. Khoo, A Near-Neutral Chloride Electrolyte for Electrically Rechargeable Zinc-Air Batteries, Journal of the Electrochemical Society 161 (14) (2014) A2080-A2086. doi:10.1149/2.0311414jes. 137

[29] Z. Liu, S. Z. E. Abedin, F. Endres, Electrodeposition of zinc films from ionic liquids and ionic liquid/water mixtures, Electrochimica Acta 89 (2013) 635-643. doi : 10.1016/j . electacta.2012.11.077. 137

[30] W. G. Sunu, D. N. Bennion, Transient and Failure Analyses of the Porous Zinc Electrode, Journal of The Electrochemical Society 127 (9) (1980) 2007-2016. doi:10.1149/1.2130054. 137, 138, 140, 141, 143, 148

[31] Z. Mao, R. E. White, Mathematical modeling of a primary zinc/air battery, Journal of the Electrochemical Society 139 (4) (1992) 1105-1114. doi:10.1149/1.2069348. 137

[32] E. Deiss, F. Holzer, O. Haas, Modeling of an electrically rechargeable alkaline Zn-air battery, Electrochimica Acta 47 (25) (2002) 3995-4010. doi:10.1016/S0013-4686(02)00316-X. 137, 140, 143

[33] J. S. Newman, C. W. Tobias, Theoretical Analysis of Current Distribution in Porous Electrodes, Journal of The Electrochemical Society 109 (12) (1962) 1183-1191. doi:10.1149/1.2425269. 137

[34] J. S. Newman, K. Thomas-Alyea, Electrochemical Systems, John Wiley \& Sons, 2004. 137, 140, 143

[35] M. J. Isaacson, F. R. McLarnon, E. J. Cairns, Current density and ZnO precipitation-dissolution distributions in $\mathrm{Zn}-\mathrm{ZnO}$ porous electrodes and their effect on material redistribution. A two-dimensional mathematical model, Journal of the Electrochemical Society 137 (7) (1990) 2014-2021. doi:10.1149/1.2086856. 137

[36] H. Ko, H. Juang, Absorption of $\mathrm{CO} 2$ by alkaline electrolyte and its effect on electrical discharge, Journal of Applied Electrochemistry 13 (6) (1983) 725-730. doi:10.1007/BF00615821. 137, 138, 148

[37] A. Latz, J. Zausch, Multiscale modeling of lithium ion batteries: thermal 
aspects, Beilstein Journal of Nanotechnology 6 (2015) 987-1007. doi : 10.3762/bjnano.6.102. 137, 139, 142

[38] A. Latz, J. Zausch, Thermodynamic consistent transport theory of Li-ion batteries, Journal of Power Sources 195 (6) (2010) 3296-3302. doi: 10.1016/j.jpowsour.2010.11.088. 137, 139, 143

[39] A. Cents, Mass Transfer and Hydrodynamics in Stirred Gas-LiquidLiquid Contactors, Ph.D. thesis, Universiteit Twente (2003). 137, 141, 143

[40] T. P. Dirkse, C. Postmus, R. Vandenbosch, A Study of Alkaline Solutions of Zinc Oxide, Journal of the American Chemical Society 76 (23) (1954) 6022-6024. doi:10.1021/ja01652a041. 138

[41] Y.-C. Chang, G. Prentice, A Model for the Anodic Dissolution of Zinc in Alkaline Electrolyte Kinetics of Initial Dissolution, Journal of The Electrochemical Society 131 (7) (1984) 1463-1468. doi:10.1149/1. 2115875. 138

[42] G. Prentice, Y.-C. Chang, X. Shan, A Model for the Passivation of the Zinc Electrode in Alkaline Electrolyte, Journal of The Electrochemical Society 138 (4) (1991) 890-894. doi : 10.1149/1.2085742. 138

[43] J. O. Bockris, Z. Nagy, A. Damjanovic, On the Deposition and Dissolution of Zinc in Alkaline Solutions, Journal of The Electrochemical Society 119 (3) (1972) 285-295. doi : 10.1149/1.2404188. 138, 140, 141, 148

[44] M.-B. Liu, G. Cook, N. P. Yao, Passivation of Zinc Anodes in KOH Electrolytes, Journal of The Electrochemical Society 128 (8) (1981) 16631668. doi: 10.1149/1.2127707. 138, 141, 143

[45] J. P. Neidhardt, D. N. Fronczek, T. Jahnke, T. Danner, B. Horstmann, W. G. Bessler, A Flexible Framework for Modeling Multiple Solid, Liquid and Gaseous Phases in Batteries and Fuel Cells, Journal of The Electrochemical Society 159 (9) (2012) A1528-A1542. doi:10.1149/2. 023209 jes. $138,141,142$

[46] D. Eberle, B. Horstmann, Oxygen Reduction on Pt(111) in Aqueous Electrolyte: Elementary Kinetic Modeling, Electrochimica Acta 137 (2014) 714-720. doi:10.1016/j.electacta.2014.05.144. 138, 141

[47] J. A. Keith, G. Jerkiewicz, T. Jacob, Theoretical investigations of the oxygen reduction reaction on $\mathrm{Pt}(111)$., ChemPhysChem 11 (13) (2010) 2779. doi:10.1002/cphc.201000286. 138

[48] H. A. Hansen, V. Viswanathan, J. K. Nørskov, Unifying Kinetic and Thermodynamic Analysis of 2e-and 4e-Reduction of Oxygen on Metal Surfaces, J. Phys. Chem. C 118 (2014) 67066718. doi:dx.doi.org/10. 1021/jp4100608. 138

[49] P. V. Danckwerts, M. M. Sharma, The absorption of carbon dioxide into solutions of alkalis and amines (with some notes on hydrogen sulphide and carbonyl sulphide), Institution of Chemical Engineers, 1966. 138, 142

[50] A. Latz, J. Zausch, Thermodynamic derivation of a ButlerVolmer model for intercalation in Li-ion batteries, Electrochimica Acta 110 (2013) 358362. doi:10.1016/j.electacta.2013.06.043. 140

[51] M. Z. Bazant, Theory of Chemical Kinetics and Charge Transfer based on Nonequilibrium Thermodynamics, Accounts of Chemical Research 46 (5) (2013) 1144-1160. doi:10.1021/ar300145c. 140

[52] Q. C. Horn, Y. Shao-Horn, Morphology and Spatial Distribution of ZnO Formed in Discharged Alkaline $\mathrm{Zn} / \mathrm{MnO} 2$ AA Cells, Journal of The Electrochemical Society 150 (5) (2003) A652-A658. doi : 10.1149/1. 1566014. 140, 147

[53] S. Szpak, C. Gabriel, The Zn-KOH System: The Solution-Precipitation Path for Anodic ZnO Formation, Journal of The Electrochemical Society 126 (11) (1979) 1914-1923. doi:10.1149/1.2128826. 140

[54] A. Nyman, M. Behm, G. Lindbergh, Electrochemical characterisation and modelling of the mass transport phenomena in LiPF6-EC-EMC electrolyte, Electrochimica Acta 53 (22) (2008) 6356-6365. doi:10.1016/ j.electacta.2008.04.023. 141

[55] F. Single, B. Horstmann, A. Latz, Dynamics and morphology of solid electrolyte interphase (SEI), Phys. Chem. Chem. Phys. 18 (2016) 1781017814. doi: 10.1039/C6CP02816K. 141

[56] Y. L. Cao, H. X. Yang, X. P. Ai, L. F. Xiao, The mechanism of oxygen reduction on $\mathrm{MnO} 2$-catalyzed air cathode in alkaline solution, Journal of Electroanalytical Chemistry 557 (2003) 127-134. doi : 10.1016/ S0022-0728(03)00355-3. 141, 148

[57] S. Weisenberger, A. Schumpe, Estimation of gas solubilities in salt solutions at temperatures from $273 \mathrm{~K}$ to $363 \mathrm{~K}$, AIChE Journal 42 (1) (1996) 298-300. doi:10.1002/aic.690420130.141, 143
[58] I. W. Eames, N. J. Marr, H. Sabir, The evaporation coefficient of water: a review, International Journal of Heat and Mass Transfer 40 (12) (1997) 2963-2973. doi:10.1016/S0017-9310(96)00339-0. 141

[59] A. H. G. Cents, D. W. F. Brilman, G. F. Versteeg, CO2 absorption in carbonate/bicarbonate solutions: The Danckwerts-criterion revisited, Chemical Engineering Science 60 (21) (2005) 5830-5835. doi:10.1016/j. ces. 2005.05.020. 141

[60] P. V. Danckwerts, Absorption by simultaneous diffusion and chemical reaction, Trans. Faraday Soc. 46 (1950) 300-304. doi:10.1039/ TF9504600300. 141

[61] S. De Groot, P. Mazur, Non-Equilibrium Thermodynamics, Dover Publications, Inc, New York, 1984. 142

[62] T. Jahnke, G. Futter, A. Latz, T. Malkow, G. Papakonstantinou, G. Tsotridis, P. Schott, M. Gerard, M. Quinaud, M. Quiroga, A. A. Franco, K. Malek, F. Calle-Vallejo, R. Ferreira De Morais, T. Kerber, P. Sautet, D. Loffreda, S. Strahl, M. Serra, P. Polverino, C. Pianese, M. Mayur, W. G. Bessler, C. Kompis, Performance and degradation of Proton Exchange Membrane Fuel Cells: State of the art in modeling from atomistic to system scale, Journal of Power Sources 304 (2016) 207-233. doi:10.1016/j.jpowsour.2015.11.041. 142

[63] T. Danner, S. Eswara, V. P. Schulz, A. Latz, Characterization of gas diffusion electrodes for metal-air batteries, Journal of Power Sources 324 (2016) 646-656. doi : 10.1016/j.jpowsour. 2016.05.108. 142

[64] J. A. Dean, N. A. Lange, Lange's handbook of chemistry, McGraw-Hill, 1999. doi: $10.1080 / 10426919008953291.143$

[65] R. Sander, Compilation of Henry's law constants (version 4.0) for water as solvent, Atmos. Chem. Phys. Discuss. 15 (2015) 4399-4981. doi : 10.5194/acp-15-4399-2015. 143

[66] W. G. Sunu, Transient and Failure Analyses of Porous Zinc Electrodes, Phd, University of California, Los Angeles (1978). 143

[67] S. Siu, J. W. Evans, Density and Viscosity Measurements of Zincate/KOH Solutions, Journal of The Electrochemical Society 144 (4) (1997) 12781280. doi:10.1149/1.1837583. 143

[68] D. Möller, Luft: Chemie, Physik, Biologie, Reinhaltung, Recht, Walter de Gruyter, 2003. 143

[69] R. E. Davis, G. L. Horvath, C. W. Tobias, The solubility and diffusion coefficient of oxygen in potassium hydroxide solutions, Electrochimica Acta 12 (3) (1967) 287-297. doi : 10.1016/0013-4686 (67) 80007-0. 143

[70] C. E. May, H. C. Kautz, Determination of the zincate diffusion coefficient and its application to alkaline battery problems, Nasa Technical Memorandum, NASA TM-73879 (1978) 1-16. 143

[71] R. N. Bhatia, K. E. Gubbins, R. D. Walker, Mutual diffusion in concentrated aqueous potassium hydroxide solutions, Transactions of the Faraday Society 64 (1968) 2091-2099. doi :10.1039/TF9686402091. 143

[72] R. E. Zeebe, On the molecular diffusion coefficients of dissolved $\mathrm{CO} 2$, HCO3-, and CO32- and their dependence on isotopic mass, Geochimica et Cosmochimica Acta 75 (9) (2011) 2483-2498. doi : 10.1016/j . gca. 2011.02.010. 143

[73] M.-B. Liu, B. Fauls, G. Cook, N. P. Yao, Conductivity of KOH Electrolyte Supersaturated with Zincate, Journal of The Electrochemical Society 128 (10) (1981) 2049-2052. doi : 10.1149/1.2127187. 143

[74] D. M. See, R. E. White, Temperature and Concentration Dependence of the Specific Conductivity of Concentrated Solutions of Potassium Hydroxide, Journal of Chemical \& Engineering Data 42 (6) (1997) 12661268. doi:10.1021/je970140x. 143

[75] T. Danner, Modeling and experimental investigation of transport processes in the porous cathode of aqueous Li-air batteries, Ph.D. thesis, Universitt Stuttgart (2015). 143

[76] P. M. Dunlap, S. R. Faris, Surface Tension of Aqueous Solutions of Potassium Hydroxide, Nature 196 (1962) 1312-1313. doi:10.1038/ 1961312a0. 143

[77] I. Manke, J. Banhart, A. Haibel, A. Rack, S. Zabler, N. Kardjilov, A. Hilger, A. Melzer, H. Riesemeier, In situ investigation of the discharge of alkaline $\mathrm{ZnMnO} 2$ batteries with synchrotron x-ray and neutron tomographies, Applied Physics Letters 90 (21) (2007) 214102. doi : 10.1063/1.2742283. 143

[78] E. L. Gyenge, J.-F. Drillet, The Electrochemical Behavior and Catalytic Activity for Oxygen Reduction of MnO2C Toray Gas Diffusion Electrodes, Journal of The Electrochemical Society 159 (2) (2012) F23-F34. doi:10.1149/2.061202jes. 143 
[79] R. Pohorecki, W. Moniuk, Kinetics of reaction between carbon dioxide and hydroxyl ions in aqueous electrolyte solutions, Chemical Engineering Science 43 (7) (1988) 1677-1684. doi:10.1016/0009-2509(88) 85159-5. 143

[80] P. Popov, Y. Vutov, S. Margenov, O. Iliev, Finite Volume Discretization of Equations Describing Nonlinear Diffusion in Li-Ion Batteries, in: Numerical Methods and Applications, Volume 6046 of the series Lecture Notes in Computer Science, Springer, Kaiserslautern, Germany, 2011, pp. 338346. doi : 10.1007/978-3-642-18466-6_40. 143

[81] A. Rinaldi, O. Wijaya, H. E. Hoster, Lithium-Oxygen Cells : An Analytical Model to Explain the Key Features in the Discharge Voltage Profiles, ChemElectroChem 3 (June) (2016) 1-8. doi:10.1002/celc . 201600184. 147 


\title{
Supplementary Information Nucleation and Growth of Zinc Oxide in Zinc-Air Button Cells
}

\author{
Johannes Stamm ${ }^{\mathrm{a}, \mathrm{b}, \mathrm{c}}$, Alberto Varzi ${ }^{\mathrm{a}, \mathrm{d}}$, Arnulf Latz ${ }^{\mathrm{a}, \mathrm{b}, \mathrm{e}}$, Birger Horstmann ${ }^{\mathrm{a}, \mathrm{b}}$ \\ ${ }^{a}$ Helmholtz Institute Ulm (HIU), Helmholtzstraße 11, 89081 Ulm, Germany \\ ${ }^{b}$ German Aerospace Center (DLR), Institute of Engineering Thermodynamics, Pfaffenwaldring 38-40, 70569 Stuttgart, Germany \\ ${ }^{c}$ Institute for Computational and Applied Mathematics, Universität Münster, Einsteinstraße 62, 48149 Münster, Germany \\ ${ }^{d}$ Karlsruhe Institute of Technology (KIT), PO Box 3640, 76021 Karlsruhe, Germany \\ ${ }^{e}$ Ulm University, Institute of Electrochemistry, Albert-Einstein-Allee 47, 89069 Ulm, Germany
}

\section{Appendix A. Parameterization}

We model the Varta PowerOne hearing aid coin cell battery PR44 type p675. Therefore, the parameters represent this battery type. Decades ago, thermodynamics and ionic transport in the aqueous alkaline electrolyte (32 weight percent $\mathrm{KOH}$ ) were accurately studied with experiments. Thus, in Appendix A.1 we describe thermodynamic parameters and in Appendix A.2 we discuss transport parameters based on the extensive literature. In contrast, the reaction kinetics are not known with sufficient accuracy. Therefore, we choose to adjust them such that the simulated discharge curves match the measured ones (see Appendix A.3). Nevertheless, we make sure that the reaction parameters are reasonable by comparing to the literature data. We want to highlight that the qualitative features of our simulation results are robust against variations of the kinetic parameters.

Basic material parameters and physical constants are given in Tab. A.4. Experiments and Simulations are performed under standard conditions (see Tab. A.3).

In our model, the void space beneath the anode lid, which compensates the volume expansion of the active material, is distributed homogeneously along the anode (see 3.4). We adjust the volume fraction of zinc to get the observed cell capacity of $460 \mathrm{mAh}$. The (initial) volume fractions and cell dimensions are stated in Tab. A.5.

\section{Appendix A.1. Thermodynamics}

Appendix A.1.1. Half-Cell Potentials

The standard half-cell potential for zinc oxidation is $\Delta \phi_{\mathrm{a}}^{0}=-1.285 \mathrm{~V}$ and for oxygen reduction is $\Delta \phi_{\mathrm{c}}^{0}=0.401 \mathrm{~V}$ at standard conditions relative to the standard hydrogen electrode [64].

\section{Appendix A.1.2. Solubilities}

The solubility in pure water depends on the partial gas pressure by Henry's law (see Eq. 32) with Henry's constants $H_{\mathrm{O}_{2}}^{\mathrm{p}, \mathrm{c}}=7.7942 \cdot 10^{4} \mathrm{~m}^{3} \mathrm{~Pa} \mathrm{~mol}_{\text {gas }}^{-1}$ and $H_{\mathrm{CO}_{2}}^{\mathrm{p}, \mathrm{c}}=2.98 \cdot 10^{4} \mathrm{~m}^{3} \mathrm{~Pa} \mathrm{~mol}_{\text {gas }}^{-1}$ for oxygen and carbon dioxide, respectively [65]. At large salt concentrations (32 wt\% $\mathrm{KOH})$, the solubility is reduced and we must take into account salting out (see Eq. 32). The Sechenov constant is approximated as [57]

$$
K^{\mathrm{s}}=\sum_{i} h_{i} c_{i}
$$

Email address: birger.horstmann@dlr.de (Birger Horstmann) 


\begin{tabular}{l|c} 
Ion & $h_{i} / \mathrm{m}^{3} \mathrm{~mol}^{-1}$ \\
\hline Potassium & $0.922 \cdot 10^{-4}$ \\
Hydroxide & $0.839 \cdot 10^{-4}$ \\
Zincate & $1.423 \cdot 10^{-4}$ \\
Carbonate & $1.423 \cdot 10^{-4}$
\end{tabular}

Table A.1. Coefficients for Sechenov constant [57] (see Eq. A.1). The value for $\mathrm{ZnOH}_{4}^{=}$is chosen to be equal to the one for $\mathrm{CO}_{3}^{=}$.

where the coefficients $h_{i}$ are given in Tab. A.1. At initial electrolyte concentrations, we find the solubilities $c_{\mathrm{O}_{2}}^{*}=13.4 \mathrm{~mol} \mathrm{~m}^{-3}$ and $c_{\mathrm{CO}_{2}}^{*}=1.1 \mathrm{~mol} \mathrm{~m}^{-3}$.

We calculate the solubility $c_{\text {sat }}$ of zincate depending on the potassium concentration $c_{\mathrm{K}}$ [66]

$$
c_{\mathrm{sat}}= \begin{cases}-0.21 c_{\mathrm{std}}+0.975 \cdot 10^{-1} c_{\mathrm{K}}+0.125 \cdot 10^{-2} \frac{c_{\mathrm{K}}^{2}}{c_{\mathrm{std}}} & \text { if } c_{\mathrm{K}}>2.1 c_{\mathrm{std}} \\ 0 & \text { else } .\end{cases}
$$

Note that zinc dissolution is possible even for $c_{\text {sat }}=0$ due to supersaturation.

Appendix A.1.3. Molar Volumes

The electrolyte density $\rho$ is [67]

$$
\rho=\left(1024.1+846.6 w_{1}+307.1 w_{1}^{2}+1039 w_{2}\right) \mathrm{kg} \mathrm{m}^{-3} .
$$

Here, the weight percentage $w_{1}$ of potassium hydroxide is defined with respect to the solution $\mathrm{H}_{2} \mathrm{O}-\mathrm{KOH}$, while that of zinc oxide $w_{2}$ is defined with respect to the whole electrolyte $\mathrm{H}_{2} \mathrm{O}-\mathrm{KOH}-\mathrm{ZnO}$.

We calculate the partial molar volumes $\bar{V}_{i}$ from the density in the following [61]. For this purpose, we introduce the molality $b_{j}:=N_{j} m_{0}^{-1}$, where $m_{0}$ denotes the mass of $\mathrm{H}_{2} \mathrm{O}$. The density is $\rho=m V_{\mathrm{e}}^{-1}$ with the electrolyte mass $m=m_{0}\left(1+\sum_{j=1}^{3} M_{j} b_{j}\right)$ and the molar masses of the salts $M_{j}$. Then the partial molar volume is

$$
\begin{aligned}
\bar{V}_{j}:=\frac{\partial V_{\mathrm{e}}}{\partial n_{j}} & =\frac{\partial}{\partial n_{j}}\left(\frac{m}{\rho}\right)=\frac{\partial}{\partial b_{j}}\left(\frac{1+\sum_{j} M_{j} b_{j}}{\rho}\right) \\
& =-\frac{1}{\rho^{2}}\left(\frac{\partial \rho}{\partial b_{j}}\right)\left(1+\sum_{i=0}^{3} b_{i} M_{i}\right)+\frac{1}{\rho} M_{j} .
\end{aligned}
$$

Molalities $b_{j}$ and weight percents $w_{j}$ are related through $w_{j}=w_{0} b_{j} M_{j}$. By summing over all species, we find $w_{0}=1 /\left(1+\sum_{j=1}^{2,3} M_{j} b_{j}\right)$ and

$$
w_{j}=\frac{b_{j} M_{j}}{1+\sum_{j=1}^{2,3} M_{j} b_{j}} .
$$

The sum includes $\mathrm{ZnO}$ for $w_{2}$, but not for $w_{1}$ here because Siu et al. define weight percent in two different ways [67].

The partial molar volume of the solvent is then determined from Eq. 44

$$
\bar{V}_{0}=M_{0}\left(\frac{1+\sum_{j=1}^{3} M_{j} b_{j}}{\rho}-\sum_{j=1}^{3} \bar{V}_{j} b_{j}\right) .
$$




\begin{tabular}{l|l|c|c} 
Ion & Notation & Value $/ \mathrm{S} \mathrm{m}^{2} \mathrm{~mol}^{-1}$ & Source \\
\hline Potassium & $\lambda_{\mathrm{K}^{+}}$ & $7.35 \cdot 10^{-3}$ & {$[64]$} \\
Hydroxide & $\lambda_{\mathrm{OH}^{-}}$ & $19.8 \cdot 10^{-3}$ & {$[64]$} \\
Zincate & $\lambda_{\mathrm{Zn}(\mathrm{OH})_{4}}$ & $9.035 \cdot 10^{-3}$ & {$[30]$} \\
Carbonate & $\lambda_{\mathrm{CO}_{3}^{=}}$ & $6.98 \cdot 10^{-3}$ & {$[64]$}
\end{tabular}

Table A.2. Ionic conductivity at infinite dilution

Carbonate is not included in the measurement stated in Eq. A.3. We choose to treat one $\mathrm{K}_{2} \mathrm{CO}_{3}$ molecules as two $\mathrm{KOH}$ molecules in the density calculations. Consequently, we determine its partial molar volume from that of $\mathrm{KOH}$, such that the density is consistent

$$
\bar{V}_{\mathrm{K}_{2} \mathrm{CO}_{3}}=\frac{M_{\mathrm{K}_{2} \mathrm{CO}_{3}}}{2 M_{\mathrm{KOH}}} \bar{V}_{\mathrm{KOH}}
$$

Note that Eq. A.3 uses the salt $\mathrm{ZnO}$, but our model uses $\mathrm{K}_{2} \mathrm{Zn}(\mathrm{OH})_{4}$. The stoichiometry (see Reaction II) gives

$$
\bar{V}_{\mathrm{K}_{2} \mathrm{Zn}(\mathrm{OH})_{4}^{\bar{y}}}=2 \bar{V}_{\mathrm{KOH}}+\bar{V}_{\mathrm{ZnO}}+\bar{V}_{\mathrm{H}_{2} \mathrm{O}}
$$

\section{Appendix A.2. Transport}

Appendix A.2.1. Diffusion

Davis et al. [69] measure and show the diffusion coefficient of oxygen in potassium hydroxide solution

$$
D_{\mathrm{O}_{2}}=\left[1.5 \cdot 10^{-9} \exp \left(-0.2878 \frac{c_{\mathrm{OH}^{-}}}{c_{\mathrm{std}}}\right)+0.4 \cdot 10^{-9}\right] \frac{\mathrm{m}^{2}}{\mathrm{~s}} .
$$

According to May et al. [70] the diffusion coefficient of zincate depends linearly on potassium ion concentration and is independent from zincate concentration

$$
D_{\mathrm{ZnOH}_{4}}=\left[-9.33 \cdot 10^{-11} \frac{c_{\mathrm{K}}}{c_{\text {std }}}+1.2 \cdot 10^{-9}\right] \frac{\mathrm{m}^{2}}{\mathrm{~s}} .
$$

The remaining diffusion coefficients stay approximately constant in the relevant electrolyte concentration range. From literature, we find the diffusion coefficient of hydroxide [71], carbonate [72], and carbon dioxide [39] to be

$$
\begin{gathered}
D_{\mathrm{OH}^{-}}=3.5 \cdot 10^{-9} \mathrm{~m}^{2} \mathrm{~s}^{-1}, \\
D_{\mathrm{CO}_{3}^{=}}=0.82 \cdot 10^{-9} \mathrm{~m}^{2} \mathrm{~s}^{-1}, \\
D_{\mathrm{CO}_{2}}=1.5 \cdot 10^{-9} \mathrm{~m}^{2} \mathrm{~s}^{-1} .
\end{gathered}
$$

\section{Appendix A.2.2. Migration}

Liu et al. [73] show that a linear mixture rule is applicable for the determination of the conductivity $\kappa$ in concentrated $\mathrm{KOH}$ based systems

$$
\kappa=\Lambda_{\mathrm{KOH}} c_{\mathrm{OH}^{-}}+2 \Lambda_{\mathrm{Zn}(\mathrm{OH})_{4}^{=}} c_{\mathrm{Zn}(\mathrm{OH})_{4}^{=}}+2 \Lambda_{\mathrm{K}_{2} \mathrm{CO}_{3}} c_{\mathrm{CO}_{3}^{=}},
$$

where the conductivity of binary potassium hydroxide solutions $\kappa_{\mathrm{KOH}}=\Lambda_{\mathrm{KOH}} c_{\mathrm{K}^{+}}$is fitted by See et al. [74] as a function of potassium concentration. The equivalent conductivities of zincate is $\Lambda_{\mathrm{Zn}(\mathrm{OH})_{4}^{=}}=$ $7 \cdot 10^{-4} \mathrm{Sm}^{2} \mathrm{~mol}^{-1}[73]$ and of carbonate are $\Lambda_{\mathrm{Zn}(\mathrm{OH})_{4}^{=}}=\left(-7.14 c_{\mathrm{K}^{+}} / c_{\mathrm{std}}+78.18\right) \cdot 10^{-4} \mathrm{Sm}^{2} \mathrm{~mol}^{-1}[64,73]$. 
A definition of transference numbers for binary electrolytes is discussed in [34]. Generalizing the definition by applying the above mentioned mixture rule, the transference number of the ion species $i$ in the electrolyte with the three salts becomes

$$
t_{i}:=\frac{c_{i}\left|z_{i}\right| \lambda_{i}}{c_{\mathrm{K}^{+}} \lambda_{\mathrm{K}^{+}}+\sum_{j=1}^{3} c_{j}\left|z_{j}\right| \lambda_{j}} .
$$

We calculate the transference numbers from the mobility at infinite dilution which are known. Values for the ionic conductivities $\lambda_{i}$ are given in table A.2.

We model the chemical potentials as dilute solutions and get its derivative with respect to the concentration

$$
\frac{\partial \mu_{i}}{\partial c_{i}}=\frac{R T}{c_{i}}
$$

\section{Appendix A.2.3. Multi-Phase Transport}

The dynamic viscosity $\eta_{\mathrm{e}}$ of aqueous potassium hydroxide solutions is given by Siu et al. [67] the permeability of the gas diffusion electrode at the initial saturation $\tilde{s}^{0}=0.63$ is $B_{\mathrm{e}}=1 \cdot 10^{-14} \mathrm{~m}^{2}[75]$. Linear interpolating of the data in [76] yields the surface tension

$$
\sigma=\left[7.2252 \cdot 10^{-5} \frac{\mathrm{m}^{3}}{\mathrm{~kg}} \rho_{\mathrm{e}}-6.1263 \cdot 10^{-4}\right] \frac{\mathrm{kg}}{\mathrm{s}^{2}}
$$

We shift the Leverett J-function [75], such that the pressure of both, gas and liquid phase, is the standard pressure at the initial saturation $\tilde{s}^{0}$

$$
\begin{aligned}
J=1.34 \cdot 10^{-3} & +4.98 \cdot 10^{-3} \exp \left(9.404\left(\tilde{s}-\tilde{s}^{0}\right)\right) \\
& -3.97 \cdot 10^{-3} \exp \left(-11.19\left(\tilde{s}-\tilde{s}^{0}\right)\right) .
\end{aligned}
$$

\section{Appendix A.3. Reactions}

The reaction kinetics are not as accurately known as transport parameters for zinc-air batteries. Therefore, we adjust the kinetics of the two electrochemical reactions to reach quantitative agreement for the discharge curves in simulation and measurement. Nevertheless, we discuss that their orders of magnitude agree with the available literature.

\section{Appendix A.3.1. Zinc Morphology and Surface Areas}

We assume that spherical zinc particles are covered by a porous zinc oxide shell (see Sec. 3). This determines the specific surface areas $A_{\mathrm{I}}$ for the zinc dissolution (see Eq. 25) and $A_{\mathrm{II}}$ for the zinc oxide precipitation (see Eq. 31). The initial radius of the zinc particles is $r_{\mathrm{Zn}}^{0}=35 \mu \mathrm{m}$ as shown in Ref. [77]. We choose the porosity of the zinc oxide film to be $\epsilon_{\mathrm{f}}=0.05$ which is quite low, but still in agreement with Ref. [44]. We adjust the critical supersaturation to be $c_{\text {crit }}=3.5 c_{\text {sat }}$ according to Ref. [44].

\section{Appendix A.3.2. Cathode Structure and Specific Surface Areas}

The reaction surface of the oxygen and carbon dioxide absorption is the gas-liquid phase boundary in the GDE. From the lifetime experiment, we find the specific surface area $A_{\mathrm{III}}=A_{\mathrm{V}}=3 \cdot 10^{2} \mathrm{~m}^{-1}$, which is quite low. In the cathode, zinc oxide precipitates on the active surface $A_{\mathrm{II}}=A_{\mathrm{IV}}$, which we keep constant during discharge. We assume that this surface coincides with the gas-liquid phase boundary $A_{\mathrm{IV}}=3 \cdot 10^{2} \mathrm{~m}^{-1}$. 


\begin{tabular}{|c|c|c|c|}
\hline Name & Notation & Value & Unit \\
\hline Temperature & $T$ & 298.15 & $\mathrm{~K}$ \\
\hline Current density & $i_{\text {cell }}$ & 100 & $\mathrm{Am}^{-1}$ \\
\hline Standard pressure & $p_{\text {std }}$ & 101325 & $\mathrm{~Pa}$ \\
\hline Standard concentration & $c_{\text {std }}$ & 1000 & $\mathrm{~mol} \mathrm{~m}^{-3}$ \\
\hline Partial pressure oxygen & $p_{\mathrm{O}_{2}^{\mathrm{g}}}$ & 21219 & $\mathrm{~Pa}$ \\
\hline Partial pressure carbon dioxide & $p_{\mathrm{CO}_{2}^{g}}^{2}$ & 39 & $\mathrm{~Pa}$ \\
\hline Standard oxygen concentration & $c_{\mathrm{O}_{2}, \mathrm{std}}$ & 0.867 & $\mathrm{~mol} \mathrm{~m}^{-3}$ \\
\hline
\end{tabular}

Table A.3. Conditions for experiment and simulation. The partial gas pressures represent ambient air and are taken from Ref. [68]. The standard oxygen concentration corresponds to equilibrium with oxygen gas at standard pressure.

\section{Appendix A.3.3. Kinetic Coefficients}

We adjust the kinetic constant $k_{\mathrm{I}}=1.8 \cdot 10^{-6} \mathrm{~mol} \mathrm{~m}^{-2} \mathrm{~s}^{-1}$ (cf. [32]) for zinc dissolution. At typical concentrations, this value corresponds to the exchange current density $i_{0} \approx 1 \mathrm{Am}^{-2}$. This value is two orders of magnitude lower than measured on pure zinc [30]. Modern zinc anodes, however, contain additives in order to suppress hydrogen evolution. These additives can also slow down zinc dissolution.

Our adjusted kinetic coefficient for oxygen reduction $k_{\mathrm{IV}}=3 \cdot 10^{-10} \mathrm{~mol} \mathrm{~m}^{-2} \mathrm{~s}^{-1}$ corresponds to the exchange current $i_{0} \approx 10^{-4} \mathrm{Am}^{-2}$. This results in the exchange current density $i_{0}^{\mathrm{GDE}} \approx 10^{-5} \mathrm{Am}^{-2}$ with respect to the cross-section of the whole GDE in approximate agreement with the measurements of Drillet et al. for carbon based gas diffusion electrodes coated with $\mathrm{MnO}_{2}$ [78].

The kinetic constant $k_{\text {III }}$ of oxygen dissolution follows from the Hertz-Knudsen equation 33 . We assume that one percent $\xi:=0.01$ of the gas molecules hitting the gas-liquid phase boundary enter the electrolyte [12]. The kinetics of $\mathrm{ZnO}$ growths is determined by the diffusion layer thickness $\delta_{\mathrm{ZnO}}=1 \mu \mathrm{m}$ resulting in kinetics similar to previous models $[32,25]$.

The kinetic coefficient of the carbonate reaction $k_{V}:=k_{\mathrm{OH}^{-}} c_{\mathrm{OH}^{-}}$(see Eq. 37) follows from the kinetic constant $k_{\mathrm{OH}^{-}}$of the rate determining step (see Reaction V.a) [79]

$$
k_{\mathrm{OH}^{-}}=8.38 \frac{\mathrm{mol}}{\mathrm{m}^{3} \mathrm{~s}} \cdot 10^{\left(0.11 c_{\mathrm{K}^{+}}+0.11 c_{\mathrm{OH}^{-}}+0.17 c_{\mathrm{CO}}\right) / c_{\mathrm{std}}}
$$

\section{Appendix A.4. Initial Conditions}

The initial conditions are given in Tab. A.6. Varta PowerOne hearing aid batteries PR44 type p675 contain $32 \mathrm{wt} \%$ potassium hydroxide electrolyte. Accordingly, we choose the concentrations of water and potassium. For numerical reasons we set small initial concentrations for carbonate and zincate. Then we calculate the hydroxide concentration, such that charge neutrality is granted.

In our model the void space on top of the anode is homogeneously distributed throughout the cell. The volume fraction of zinc is adjusted to give the observed cell capacity of $460 \mathrm{mAh}$ (see Tab. A.5). The initial zinc particle radius is $r_{\mathrm{Zn}}^{0}=35 \mu \mathrm{m}$ [77]. 


\begin{tabular}{l|l|c|c} 
Name & Notation & Value & Unit \\
\hline $\begin{array}{l}\text { Ideal gas constant } \\
\text { Faraday constant }\end{array}$ & $R$ & 8.3144 & $\mathrm{~J} \mathrm{~mol}^{-1} \mathrm{~K}^{-1}$ \\
Boltzmann constant & $F$ & 96485 & $\mathrm{C} \mathrm{mol}^{-1}$ \\
$\mathrm{~m}^{2} \mathrm{~kg} \mathrm{~s}^{-2} \mathrm{~K}^{-1}$
\end{tabular}

Table A.4. Basic material parameters and physical constants [64].

\begin{tabular}{l|c|ccc|c} 
Name & Notation & Ano. & Sep. & Cat. & Unit \\
\hline Cell diameter & & & $11 \cdot 10^{-3}$ & & $\mathrm{~m}$ \\
Length & $L_{\mathrm{a}}, L_{\mathrm{s}}, L_{\mathrm{c}}$ & $4.5 \cdot 10^{-3}$ & $0.1 \cdot 10^{-3}$ & $0.3 \cdot 10^{-3}$ & $\mathrm{~m}$ \\
\hline Volume fraction & & & & & \\
$\quad$ Zinc & $\epsilon_{\mathrm{Zn}}^{0}$ & 0.185 & - & - & - \\
Zinc oxide & $\epsilon_{\mathrm{ZnO}}^{0}$ & $1 \cdot 10^{-7}$ & $1 \cdot 10^{-7}$ & $1 \cdot 10^{-7}$ & - \\
Inactive material & $\epsilon_{\text {inact }}^{0}$ & - & 0.185 & 0.185 & - \\
Electrolyte & $\epsilon_{\mathrm{e}}^{0}$ & 0.515 & 0.515 & 0.515 & - \\
$\quad$ Gas phase & $\epsilon_{\mathrm{g}}^{0}$ & 0.3 & 0.3 & 0.3 & - \\
Initial zinc particle diameter & $r_{\mathrm{Zn}}^{0}$ & 75 & & & $\mu \mathrm{m}$
\end{tabular}

Table A.5. Geometry for simulating the VARTA PowerOne button cell PR44 type p675.

\begin{tabular}{l|c|c|c} 
Name & Notation & Value & Unit \\
\hline Density electrolyte & $\rho_{\mathrm{e}}^{0}$ & 1301 & $\mathrm{~kg} \mathrm{~m}^{-3}$ \\
\hline Concentration & & & \\
Water & $c_{\mathrm{H}_{2} \mathrm{O}}^{0}$ & 49105 & $\mathrm{~mol} \mathrm{~m}^{-3}$ \\
Potassium & $c_{\mathrm{K}^{+}}^{0}$ & 7419.9 & $\mathrm{~mol} \mathrm{~m}^{-3}$ \\
Oxygen & $c_{\mathrm{O}_{2}}$ & 0.0134 & $\mathrm{~mol} \mathrm{~m}^{-3}$ \\
Hydroxide & $c_{\mathrm{OH}^{-}}^{0}$ & 7417.9 & $\mathrm{~mol} \mathrm{~m}^{-3}$ \\
Zincate & $c_{\mathrm{ZnOH}_{4}^{=}}^{0}$ & 1 & $\mathrm{~mol} \mathrm{~m}^{-3}$ \\
Carbonate & $c_{\mathrm{CO}_{3}^{=}}^{0}$ & $10^{-8}$ & $\mathrm{~mol} \mathrm{~m}^{-3}$
\end{tabular}




\section{Appendix B. Experimental Sequence}

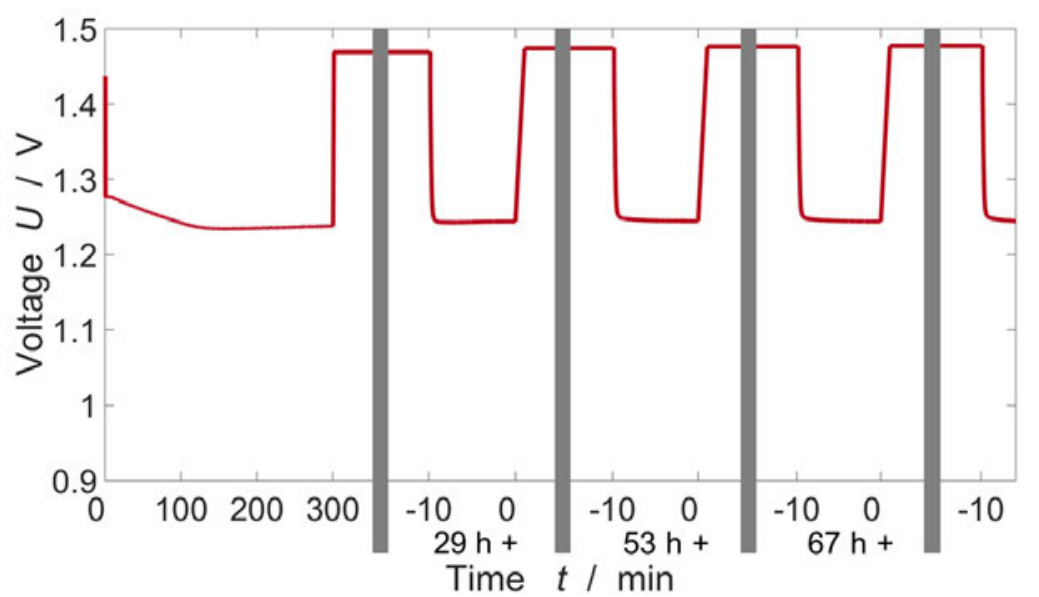

Figure B.1. Lifetime analysis at $100 \mathrm{Am}^{-2}$. The voltage is shown as a function of measurement time. After an initial discharge for $5 \mathrm{~h}$, the cell is discharged for ten minutes every day. The figure depicts the measurement in the first four days, the gray arrays separate the measurements on different days.

\section{Appendix C. Carbon Dioxide Filter}

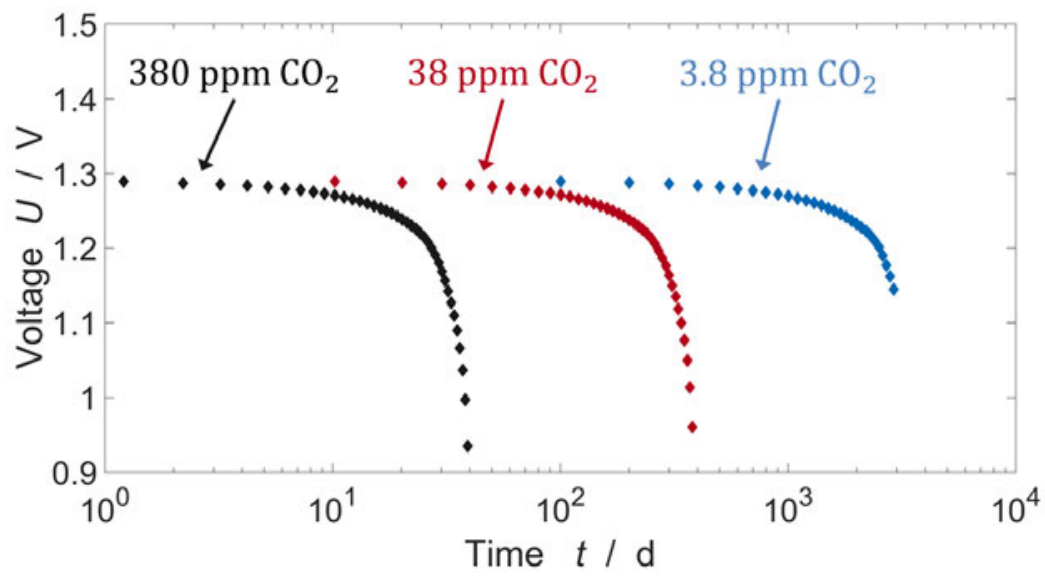

Figure C.2. Simulated lifetime analysis at $100 \mathrm{Am}^{-2}$. The voltage is shown as a function of measurement time. The discharge proceeds with varying carbon dioxide content in the feed gas. The voltage is measured every $24 \mathrm{~h}, 240 \mathrm{~h}, 2400 \mathrm{~h}$ for $380 \mathrm{ppm} \mathrm{CO}_{2}$, $38 \mathrm{ppm} \mathrm{CO} 2,3.8 \mathrm{ppm} \mathrm{CO}_{2}$, respectively. We find that the lifetime is approximately inversely proportional to the carbon dioxide content. 
Appendix D. Battery Cycling
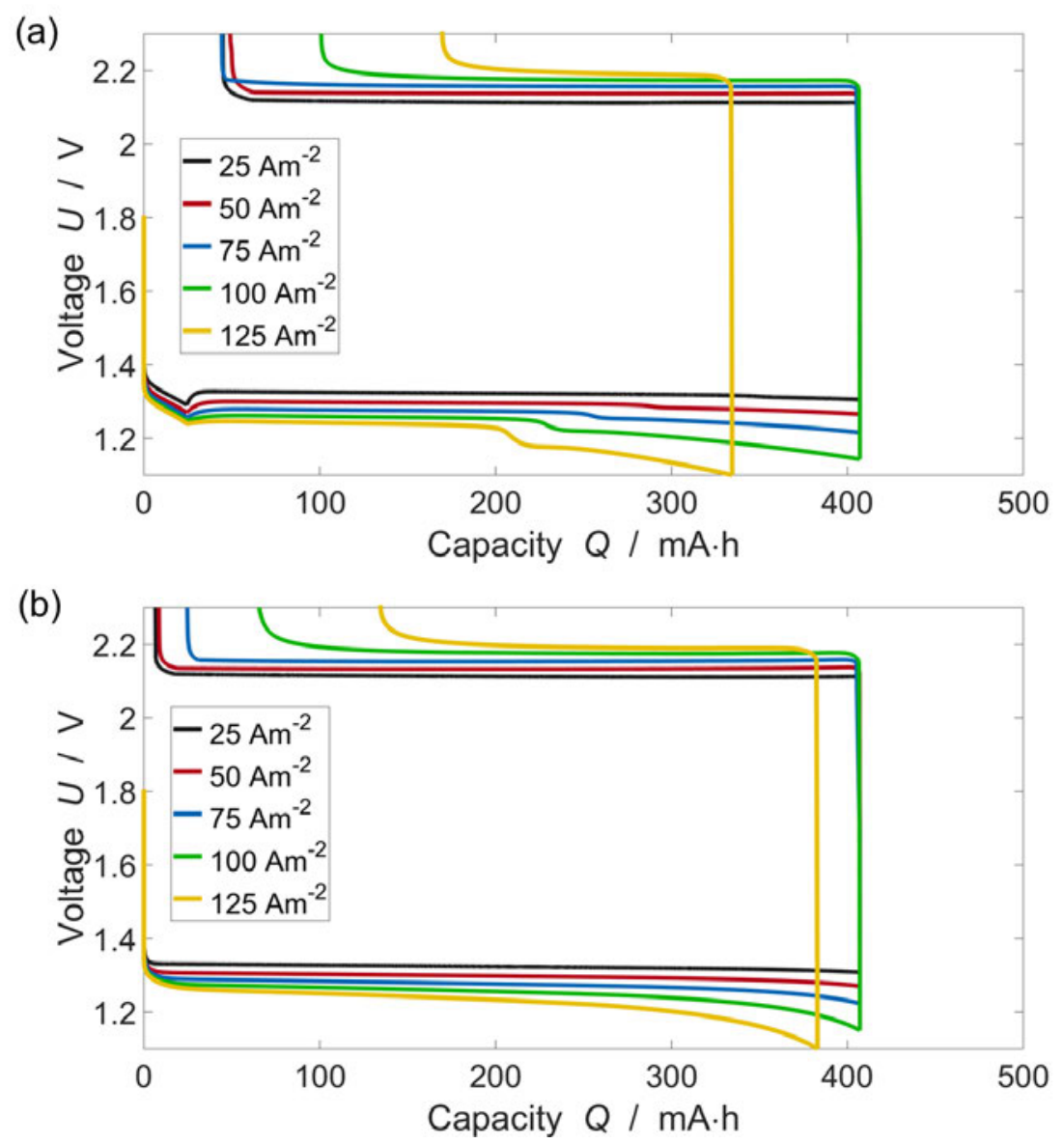

Figure D.3. Simulated voltage curves during discharge and charge as a function of discharged capacity at various current densities. The discharge proceeds to $90 \%$ capacity $Q=407 \mathrm{mAh}$ or to the voltage cut-off at $U=1.1 \mathrm{~V}$. The initial anode consists of (a) pure $\mathrm{Zn}$ and (b) a mixture of 2 volume percent $\mathrm{ZnO}$ and 98 volume percent $\mathrm{Zn}$. 